\title{
Balancing Frontliners' Customer- and Coworker-directed Behaviors when Serving Business Customers
}

Van der Borgh, Michel; de Jong, Ad; Nijssen, Edwin J.

\author{
Document Version \\ Accepted author manuscript \\ Published in: \\ Journal of Service Research \\ DOI: \\ $10.1177 / 1094670519835313$ \\ Publication date: \\ 2019 \\ License \\ Unspecified
}

Citation for published version (APA):

Van der Borgh, M., de Jong, A., \& Nijssen, E. J. (2019). Balancing Frontliners' Customer- and Coworker-directed Behaviors when Serving Business Customers. Journal of Service Research, 22(3), 323-344.

https://doi.org/10.1177/1094670519835313

Link to publication in CBS Research Portal

\section{General rights}

Copyright and moral rights for the publications made accessible in the public portal are retained by the authors and/or other copyright owners and it is a condition of accessing publications that users recognise and abide by the legal requirements associated with these rights.

\section{Take down policy}

If you believe that this document breaches copyright please contact us (research.lib@cbs.dk) providing details, and we will remove access to the work immediately and investigate your claim.

Download date: 26. Apr. 2023
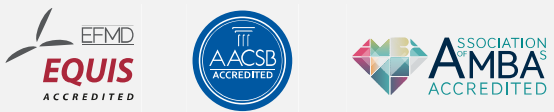


\title{
Balancing Frontliners' Customer- and Coworker-directed Behaviors when Serving Business Customers
}

\author{
Michel Van der Borgh, Ad de Jong, and Edwin J. Nijssen
}

Journal article (Accepted manuscript*)

\section{Please cite this article as:}

Van der Borgh, M., de Jong, A., \& Nijssen, E. J. (2019). Balancing Frontliners' Customer- and Coworkerdirected Behaviors when Serving Business Customers. Journal of Service Research, 22(3), 323-344. https://doi.org/10.1177/1094670519835313

DOl: https://doi.org/10.1177/1094670519835313

Copyright (C) The Author(s) २०19. Reprinted by permission of SAGE Publications.

* This version of the article has been accepted for publication and undergone full peer review but has not been through the copyediting, typesetting, pagination and proofreading process, which may

lead to differences between this version and the publisher's final version AKA Version of Record. 


\title{
Balancing Frontliners' Customer and Coworker Directed Behaviors when Serving Business Customers
}

\author{
Michel van der Borgh* \\ Associate Professor of Marketing \\ Copenhagen Business School \\ Department of Marketing \\ Solbjerg Plads 3, 2000 Frederiksberg F, Denmark \\ Phone: + 4538152100 \\ mvdb.marktg@cbs.dk \\ Ad de Jong \\ Professor of Marketing \\ Copenhagen Business School \\ Department of Marketing \\ Solbjerg Plads 3, 2000 Frederiksberg F, Denmark \\ Phone: +4538152100 \\ adj.marktg@,cbs.dk \\ Edwin J. Nijssen \\ Professor of Technology Marketing \\ Eindhoven University of Technology \\ Department of Industrial Engineering \& Innovation Sciences \\ P.O. Box 513, $5600 \mathrm{MB}$ Eindhoven, The Netherlands \\ e.j.nijssen@tue.nl
}

Keywords: product-service solutions; frontline employees; customer-directed behaviors; coworker-directed behaviors; role balance theory.

* Corresponding author

Accepted for publication in the Journal of Service Research This is a pre-print (post-peer review \& non-publisher's document). 


\title{
Balancing Frontliners' Customer- and Coworker-Directed Behaviors when Serving Business Customers
}

\author{
ABSTRACT
}

In this digital era, where many product-oriented business-to-business (B2B) companies are shifting to a product-service systems approach, frontline employees (FLEs) are urged to complement customer-directed behaviors with coworker-directed prosocial behaviors to achieve optimal performance. Surprisingly, little is known about the relationship between FLEs' coworker-directed and customer-directed behaviors in product-service systems settings. This research addresses this void and serves two purposes. First, drawing on role balance theory the authors develop and test a model of an FLE's relative emphasis on serving coworkers (i.e., helping) relative to the emphasis on serving business customers (i.e., proactive selling) as well as the antecedents and consequences of customer-coworker (im)balance. Second, the authors propose that managers can influence antecedents and consequences through an incentive system and access to information sources, respectively. Multivariate time-lagged analyses using survey and secondary performance data reveal that customer-coworker balance is beneficial for an FLE's performance, especially when leveraging their coworkers as a prime information source. Interestingly, the increasingly damaging impact of an imbalance toward customer-directed behaviors can be countered by using the IT system. Also of interest is that managers can correct imbalance - caused either by work group identification or expected customer demand - via individual-based incentives.

Keywords: product-service solutions; frontline employees; customer-directed behaviors; coworker-directed behaviors; role balance theory 
In this digital era, many product-oriented business-to-business (B2B) companies are moving toward a product-service systems approach in which product solutions are complemented with new service solutions, such as leasing, automatic upgrading, and remote monitoring maintenance, to provide improved product functionality (Ostrom et al. 2010). In these productoriented firms, frontline employees' (FLEs) core tasks traditionally revolved around customerdirected behaviors, including activities such as identifying customer needs, initiating customer encounters, and overcoming customer complaints and problems.

The core challenge for managers in a product-service systems setting is to create a service mindset in which FLEs learn by harnessing both customer and coworker knowledge (Ostrom et al. 2010). The complexities of these product-service offerings require greater flexibility, integrative service effort, and team-based collaboration among FLEs. As a result, FLEs must complement their customer-directed behaviors with coworker-directed behaviors, which aim to help peers with or prevent the occurrence of task-related problems.

While time is scarce at the frontline and should be spent well, top-performing companies invest heavily in increasing "peer time", as engaging with coworkers reportedly improves overall FLE performance (Frick and Kovac 2017). For example, Siemens has invested in the development of a social media application to facilitate connections and synergies among FLEs, enabling them to learn from coworkers' successfully implemented solutions, which was ultimately beneficial for the FLEs own performances (Müller 2007). Indeed, many FLE leaders consider improving the effective sharing of best practices between coworkers a top priority (i.e., 49\%; CSO Insights 2014), yet time spent with coworkers may also go at the expense of "customer time". The question is how to balance these tasks at the frontline.

\section{[INSERT TABLE 1 ABOUT HERE]}

Previous research has demonstrated the importance of both customer-directed and coworker-directed behaviors in attaining high FLE performance, satisfied customers, and job satisfaction. Table 1 provides an overview of the studies in marketing and related disciplines 
examining customer- and coworker-directed behaviors. We identify three challenges based on the information presented in Table 1. First, although the extant research indicates the importance of customer- and coworker-directed behaviors at the frontline, only a few studies consider the issue of (im)balance (see column 'Consideration of Balance'). Balancing duties and expectations from internal (coworkers) and external (customers) stakeholders is not an easy task, and its desirability can be questioned (Plouffe et al. 2016). Growing theoretical (Bergeron 2007) and empirical evidence (e.g., Podsakoff and Mackenzie 1994) suggests that spending more resources on coworkers may lead to imbalance and come at the expense of the customers, resulting in lower performance outcomes (Locke et al. 1994). However, Rapp et al. (2013) have demonstrated that spending more time helping coworkers does not have to be detrimental for FLE performance if FLEs possess proficient time management skills. This ongoing debate concerning the role of balance underlines the importance to conduct further research examining this concept.

In response, we introduce the concept of customer-coworker balance, which refers to an FLE's equal engagement in customer- and coworker-directed service behaviors and extends role balance theory (e.g., Aryee, Srinivas, and Tan 2005; Marks and MacDermid 1996) to understand fully the intrinsic relationship between both types of behaviors. While the concept of balance is not new to marketing research (e.g., Evanschitzky et al. 2011), we are the first to conceptualize and operationalize role (im)balance across the full range of combinations regarding presence (i.e., balance or imbalance) and direction (i.e., positive and negative balance; over/underemphasizing coworker-directed behaviors).

Although the use of such broad concepts of behavior is useful and versatile, scholars urge researchers to select carefully specific concepts, that is, fitting the job or occupational sector being studied (cf. Bakker, Demerouti, and Verbeke 2004). Following this advice, we investigate helping behaviors directed at coworkers and proactive selling directed at customers as representatives of these two broader categories. Helping refers to providing proactive 
assistance to coworkers and preventing work-related problems regarding the sale of the newly introduced product-service solutions (Van der Borgh, De Jong, and Nijssen 2017b). Proactive selling reflects an FLE's initiative in selling newly introduced product-service solutions, anticipating opportunities rather than threats, and persisting in offering such new solutions until customers have adopted them (e.g., Pitt, Ewing, and Berthon 2002). Combining these two behaviors helps address the main challenge FLEs face when selling product-service systems; the need to align these customer- and coworker-directed behaviors.

Second, we test the widely held assumption that the best-performing FLEs engage in both customer- and coworker-directed behaviors (Mayer and Greenberg 2006) and under which conditions this assumption holds. Few empirical studies have examined the boundary conditions of customer and coworker-directed behaviors, and no study has considered how these conditions affect (im)balance (see Table 1, 'Contingencies'). In response, we adopt a broader view by exploring how different types of information sources (i.e., coworker, IT system, and internal business team) moderate the effect of (im)balance on FLEs' performances when delivering product-service combinations. Third, previous research has largely ignored how managers can control the formation of coworker-directed (im)balance by FLEs. Frontline relationships generally have low interdependence and, as a result, FLEs tend to focus on maximizing personal utility without concern for others (Grant and Patil 2012). While managers then often turn to group incentive schemes to foster helping behaviors directed at coworkers, we expect adverse effects of group incentives in such complex, loosely knit environments in which FLEs must combine multiple roles (Lim and Chen 2014). We consider the contingent role of group incentives to examine this phenomenon.

Next, we build on role balance theory to develop a model of FLEs' engagement in customer-directed (proactive selling) and coworker-directed (helping coworkers) and account for their level of (im)balance. We then develop our hypotheses. After discussing our empirical study, we close with a discussion of the study's theoretical and managerial implications. 


\section{CONCEPTUAL FRAMEWORK}

\section{Role Balance Theory}

In this study, we aim to examine how FLEs can effectively balance customer- and coworker-directed behaviors when developing and delivering product-service solutions. We draw on role balance theory (e.g., Greenhaus, Collins, and Shaw 2003; Marks and MacDermid 1996) and role theory (Katz and Kahn 1978). Role balance refers to the equal engagement of an individual in performing each role in his or her total role system (Marks and MacDermid 1996). Role balance theory contends that full engagement, that is, high participation in all role domains, reflects a condition of a positive role balance, which contrasts negative role balance in which individuals are fully disengaged (i.e., low participation in all role domains). Role imbalance occurs when an individual overemphasizes one role, such as family or work, over the other. Importantly, balance is relative and does not reflect actual effort in terms of hours.

A key assumption of role balance theory is that balanced employees perform better. First, engagement in multiple roles buffers employees from the negative experiences encountered in any one role (Barnett and Hyde 2001). For instance, when an FLE fails to successfully design and deliver a new product-service solution to a customer, he or she may still be able to use this experience to help colleagues facing similar challenges. Balance then reduces role-overload, enhances role-ease, and fosters a more positive mindset (Marks and MacDermid 1996). Furthermore, balanced employees have developed routines and time management skills, enabling them to meet all role demands and making them more effective. If employees overemphasize one role over other roles, this imbalance generally leads to conflict and frictions, which can lower overall performance because the expectations and goals of each role domains are not met. In a frontline setting, positive balance is associated with a more enduring engagement to overcome task-related problems for oneself and coworkers.

We build on role theory to understand why FLEs engage in specific roles. Role theory (Katz and Kahn 1978) asserts that role behavior is more a function of the social setting than 
employee characteristics. A focal FLE's role behavior is mainly determined by his or her perception of role expectations communicated by stakeholders of the role set (Katz and Kahn 1978; McAllister et al. 2007). Role theory contends that to acquire insight into FLE role compliant or deviant behavior, it is essential to study the focal FLE's perceptions of role expectations rather than the actual signals sent by the role set, as only the former directly influences behavior (Katz and Kahn 1978). The full range of role expectations in the role set should be considered to fully understand role behavior (McAllister et al. 2007). In boundaryspanning settings, the role set generally consists of (1) customers, (2) coworkers, and (3) the FLE manager, but also (4) the internal business team (Plouffe et al. 2016).

Whether an FLE's perception of stakeholder expectations translates into actual rolecongruent behavior depends on the instrumentality of these role expectations, which refer to the extent to which role expectations are related to performance outcomes regarding rewards and punishment (McAllister et al. 2007). Only when FLEs think there is a link between stakeholder (e.g., manager) expectations - concerning desired behaviors (e.g., offering new product-service solutions) - and consequences for personal outcomes (e.g., job promotion), can it influence their behavior. Hence, we focus on the expectations related to customers, coworkers, and the manager, since these stakeholders have a direct influence on the consequences of FLE task performance. Specifically: (1) customers who will or will not adopt product-service combinations, (2) coworkers who praise or criticize or punish members' behaviors (e.g., not reciprocate) relative to work group goals, values, and norms, and (3) managers who positively or negatively evaluate the FLE's performance.

We posit that FLEs exhibiting role balance are better capable of meeting the multiple role expectations within the role set and engage more actively in multiple behavioral roles. That is, these FLEs display role balance because they understand that it fosters their performance.

Although many variables may determine FLE behavior, we are guided by the rich marketing literature on FLE behavior and role balance theory in selecting role-specific 
antecedents. Research has demonstrated that expected customer demand and work group identification are core drivers of proactive selling and helping behavior, respectively (e.g., Blader and Tyler 2009; Wieseke, Homburg, and Lee 2008). This evidence is consistent with a focal FLE's belief that addressing the concerns of customers and/or coworkers effects their performance and personal outcomes (i.e., instrumentality).

\section{The Moderating Role of Information Sources on the (Im)Balance-Performance Relationship}

Consistent with role theory, we focus on the contingent effect of information sources. Role theory emphasizes that the efficacy of role execution is contingent on the extent to which there is informational interdependence with other roles in the role set (Biddle 2013). Source informational interdependence can be characterized regarding personal or impersonal versus biased or unbiased information sources (Moriarty Jr and Spekman 1984). These information sources can be biased when the source itself directly benefits from a particular outcome generated by the focal FLE (e.g., coworkers). We consider three important information sources which can be classified as follows: (1) coworkers are personal, biased sources of information, (2) the internal business unit is a personal, unbiased source of information, and (3) the IT system is an impersonal, unbiased source of information. Note that informational interdependence is lowest if an FLE mainly draws information from the IT system.

The two characteristics of interdependence affect the efficacy of role execution in different ways. First, the degree to which information sources are (im)personal determines the extent to which rich and tacit information can be exchanged between the focal FLE and information source (e.g., Tamer Cavusgil, Calantone, and Zhao 2003). More complex, rich, and tacit information is more easily transferred and internalized when the information source is personal. Information gained from coworkers provides more detail on and insight into how to manage a problem, while information from the more impersonal information system generally cannot capture tacit information but primarily contains explicit information, which can be easily codified and transferred without knowing the specific context (e.g., customer). 
Second, the degree to which an information source is (un)biased affects whether the FLE is reciprocated with high-quality advice and information (Biddle 2013). Biased information sources such as coworkers benefit from interactions with the focal FLE, either directly by receiving help and advice from the focal FLE (Van der Vegt, Bunderson, and Oosterhof 2006), or indirectly via, for instance, reputational benefits of being associated with the focal FLE (Tyler and Blader 2003). In contrast to unbiased information sources, biased information sources have expectations from the focal FLE's specific role behaviors and reward (or punish) the focal FLE for meeting (or not meeting) these expectations by adjusting their reciprocation efforts accordingly (Agneessens and Wittek 2011).

\section{The Moderating Role of Group-Based Rewards in Shaping (Im)Balance}

Role theory indicates that managers can shape subordinates' role engagement by influencing the instrumentality of role expectations via incentive systems (Katz and Kahn 1978). Given that most FLEs who deliver complex solutions such as product-service system solutions operate in work groups (e.g., Menguc et al. 2016), the most prevalent tool for managers to shape FLE attitudes and behaviors are rewards emphasizing either the work group or the individual's own task via a group-based and/or an individual-based component (Lim and Chen 2014). While research on group-based incentives is scant, the underlying rationale of emphasizing the group-based component is to make FLEs more aware of their duties toward the group, thereby increasing their emphasis on helping coworkers with task execution (Lim and Chen 2014). We posit that FLEs' perceptions about the importance of group rewards are likely to affect the drivers of customer-coworker (im)balance. For instance, emphasizing group-based rewards may undermine the intrinsic motivation of FLEs to help coworkers (Deci, Koestner, and Ryan 1999). In addition, research has indicated that group-based rewards make FLEs feel more dependent on other members' contributions (Lim and Chen 2014). This higher dependence makes FLEs feel they have less control over the total reward (e.g., commission) 
they receive, thereby lowering perceptions of instrumentality, which should influence whether FLEs act on expectations communicated by their role set.

\section{Conceptual Framework and Definitions}

Figure 1 depicts our conceptual model, which centers on an FLE's level of customercoworker (im)balance. Here, we examine how customer-coworker (im)balance influences FLE performance for product-service offerings. Specifically, we distinguish between the level of balance and the direction and degree of imbalance. In this study, balance resembles a situation in which the level of customer-directed behavior matches the level of coworker-directed behavior. Consistent with role balance theory, we refer to equally high engagement in both behavioral roles as positive balance and equally low engagement in both roles as negative balance (Marks and MacDermid 1996). On the other hand, FLE imbalance occurs when the levels of customer- and coworker-directed behavior do not match. Given that customerdirected behaviors are considered the primary task by many FLEs, we focus on the overemphasis or underemphasis of coworker-directed behaviors relative to customer-directed behaviors. Finally, given that the effect of (im)balance on FLE performance does not occur in a social vacuum, we also consider the contingent role of information sources consulted by the focal FLE, that is, coworkers, the IT system, and internal business team.

For the antecedents, we posit that FLE engagement in customer- and coworker-directed behaviors is differentially influenced by expected customer demand and work group identification. Expected customer demand is an FLE's momentary belief concerning the likelihood that spending effort on the sale of product-service solutions creates customer demand and, ultimately, a customer's adoption of that solution (Wieseke, Homburg, and Lee 2008). Previous research has indicated that in B2B settings, customers primarily learn from FLEs about new offerings, (i.e., a push marketing strategy) resulting in a strong effortperformance relationship, and hence, high instrumentality (e.g., Fu et al. 2010). Work group identification can be defined as the perception to which an individual member feels 
emotionally attached to, involved with, and committed to the work group's goals, norms, and values (Allen and Meyer 2000). Managers can influence the instrumentality of these drivers by installing group-based versus individual-based incentives.

[INSERT FIGURE 1 ABOUT HERE]

\section{HYPOTHESIS DEVELOPMENT}

\section{Effect of Customer-Coworker (Im)Balance on FLE Performance}

Our theoretical rationale for the effect of role balance and imbalance on FLE performance in a product-service system context consists of three elements: (1) customerdirected behaviors associated with access to important customer resources (e.g., information about specific customer needs and problems), (2) coworker-directed behaviors associated with access to important coworker resources (e.g., reciprocity regarding help and advice, reflecting on own selling activities), and (3) FLE performance for product-service solutions results from the interaction between customer- and coworker-directed behaviors. We posit that balance indicates a more conscious FLE who engages in both behavioral roles for instrumental reasons.

If there is FLE customer-coworker balance, the FLE is better able to effectively address customer needs because this employee better understands idiosyncratic customer needs via customer-directed behaviors and how to effectively address unique situations through best practices. The marketing literature suggests that FLE performance is a function of both customer- and coworker-directed behaviors (Bolander et al. 2015; Gonzalez, Claro, and Palmatier 2014). Negative customer-coworker balance (i.e., a low-level of emphasis on both role domains) hinders an effective and efficient development of product-service solutions, for instance, how to effectively manage bottlenecks during the customer interaction, but still offers solutions aligned with customer needs. In contrast, a positive role balance (i.e., a high level of emphasis on both domains) enables an FLE to quickly understand how new product-service system offerings align with specific customer needs. Thus, role balance in itself leads to better performance, but more quickly when engagement is higher (i.e., positive role balance). 
Support for this argument is evident research on the importance of time management skills (Rapp, Bachrach, and Rapp 2013). FLEs who are skilled time managers are likely better able to effectively generate and leverage reciprocal help from coworkers. Similarly, Plouffe and Grégoire (2011) have demonstrated that FLEs who consciously engage in behaviors which improve their situation have access to more organizational resources and therefore perform better. Following this, we posit that an FLE who exhibits customer-coworker role balance will perform better than coworkers who do not exhibit role balance and that this effect is larger when role balance is positive. Hence, we postulate:

$\mathrm{H}_{1}$. A more positive customer-coworker balance leads to a higher level of FLE performance.

Customer-coworker imbalance weakens an FLE's ability to learn how to effectively address customer problems. More specifically, we posit that imbalance lowers task performance through either a lack of generic knowledge, that is, best practices, or the failure to understand idiosyncratic customer problems and needs. Furthermore, we expect that the negative effect is more severe with increasing levels of imbalance, namely, overemphasizing or underemphasizing coworker-directed behaviors. If either generic or idiosyncratic information is incomplete, FLEs are unable to adapt effectively to the situation at hand. When FLEs underemphasize coworker-directed behaviors relative to customer-directed behaviors, they have less opportunity to reflect and elaborate on their ideas, routines, and task-related skills and then match idiosyncratic needs with available product-service solutions (Webb 1989). In contrast, when FLEs overemphasize coworker-directed service behaviors, they may fail to understand fully and overcome idiosyncratic customer problems. Yet, when the extent of an imbalance is small, the negative effects are also expected to be small. Hence:

$\mathrm{H}_{2}$. Higher customer-coworker imbalance leads to increasingly lower FLE performance.

\section{Moderating Effect of Primary Information Sources Consulted}


We argue that when an FLE primarily consults coworkers on how to develop and deliver product-service solutions, this approach should lead to a positive effect of customer-coworker balance on performance. First, the personal nature of this action increases the chance that larger amounts of rich and tacit knowledge are exchanged. Second, coworkers are biased in the sense that they often expect certain role behaviors from the focal FLE. When the focal FLE acts as a good citizen (e.g., high level of emphasis on both domains), he or she creates "credit slips" with coworkers (Agneessens and Wittek 2011), which increase reciprocation regarding highquality information and advice. In contrast, at low levels of engagement, his or her coworkers are less likely to reciprocate. Following this, we posit,

$\mathrm{H}_{3 \mathrm{a}}$. When FLEs prefer coworkers as an information source over the internal business unit or IT system, positive customer-coworker balance has a stronger positive effect on FLE performance.

Extending the notion of information richness and reciprocity, we argue that customercoworker imbalance has a weaker negative impact on performance when FLEs source their information from coworkers. Previous studies have indicated that personal interaction and information exchange is especially important in situations where information is highly tacit (Madhavan and Grover 1998), a situation highly prevalent when delivering product-service solutions. Yet, the exchange of highly tacit information requires commitment from both information exchange partners since the interchange takes more time and effort to transfer this type of information, implying that coworkers only reciprocate (i.e., spend scarce time and share useful tacit information with the focal FLE) if they are committed to doing so. Previous studies have also demonstrated that commitment can result from having expertise in a particular role domain (Van der Vegt, Bunderson, and Oosterhof 2006). Along this line, we argue that when an FLE exhibits customer-coworker imbalance, he or she signals to coworkers to be more experienced in either servicing coworkers or customers. Either way, signaling this rolecongruent behavior to coworkers may increase this coworker's status in the work group as the 
"go-to" person for help or how to handle unique customer problems. This status makes coworkers more willing and committed to reciprocate when asked for help. Hence:

$\mathrm{H}_{3 \mathrm{~b}}$. When FLEs prefer coworkers as an information source over the internal business unit or IT system, customer-coworker imbalance has a weaker negative effect on FLE performance.

\section{Drivers of Customer-Coworker (Im)Balance}

Expected customer demand. A key driver of customer-directed behavior is the FLE's perceived expectancy that goals can be obtained. FLEs often evaluate a product-service offering from the customer's point of view (Wieseke, Homburg, and Lee 2008), that is, assessing a solution's attributes, added value over competing solutions, difficulty of use, and implementation by a customer, to determine whether it is worthwhile to exert effort designing and offering new product-service solutions. While previous studies have reported that expected customer demand positively impacts an FLE's adoption of an innovation (i.e., brand adoption; Wieseke, Homburg, and Lee 2008), it also may increase role stress as certain opportunities should not be foregone (i.e., opportunity costs). This effect is likely to be larger for more prestigious selling activities such as newly introduced product-service systems. In such conditions, the role balance research (Aryee, Srinivas, and Tan 2005) contends that in complex task environments (e.g., B2B selling), challenging demands, that is, when customer demand for innovative product-service solutions is high, may lead to a psychological overemphasis on uncompleted tasks. As a result, a focal FLE is less able to effectively respond to the demands of other roles in his or her role set (Greenhaus, Collins, and Shaw 2003). This overemphasis on customer-directed behaviors may lead to cognitive depletion, which then negatively influences one's motivation to respond to the demands of other domains (Aryee, Srinivas, and Tan 2005). High levels of customer demand may preoccupy an FLE such that it comes at the expense of performing coworker-directed behaviors tasks. As a result, an FLE experiences an imbalance in customer- and coworker-directed behaviors (i.e., unequal engagement). Thus, we posit: 
$\mathrm{H}_{4}$. An FLE's expected customer demand increases customer-coworker imbalance; it has a stronger positive effect on customer-directed behaviors than on coworkerdirected behaviors

Work group identification. Work group identification is believed to be the primary driver of coworker-directed behaviors, including helping coworkers with their task execution (Tyler and Blader 2003). In line with prior studies, we expect a positive effect of identification on coworker-directed behaviors. Yet, the role balance literature emphasizes that high commitment to a particular role may undermine the potential for role balance (Aryee, Srinivas, and Tan 2005). High commitment to the work group's goals, values, and norms increases the focal FLE's concern for problems within the work group, thereby increasing neglect for other roles. Consistent with previous research demonstrating that involvement in one role is linked to an underemphasis of the other role (e.g., Aryee, Srinivas, and Tan 2005; Greenhaus, Collins, and Shaw 2003), we expect that work group identification will lead to imbalance, that is, higher engagement in coworker-directed behaviors than in customer-directed behaviors. Hence:

$\mathrm{H}_{5}$. An FLE's work group identification increases customer-coworker imbalance; it has a stronger positive effect on coworker-directed behaviors than on customerdirected behaviors.

\section{Moderating Effect of Group-Based Rewards}

Implementing group-based rewards inherently increases the psychological strain of FLEs to adhere simultaneously to multiple duties, that is, pursuing individual and group goals, and as such, lowers role clarity (Langfred and Moye 2004). Role balance theory (Sumer and Knight 2001) asserts that employees resort to compensation tactics under such a stressful condition (i.e., when one has low control over obtaining group rewards) by becoming more involved in the domains where they perceive they have more control over the outcomes (i.e., executing their tasks and performing well). The consequence of such compensation tactics is a higher imbalance between customer- and coworker-directed behaviors. More specifically, we expect that emphasizing group-based rewards will make FLEs with high work group identification relatively more engaged to execute customer-directed behaviors, while FLEs with high 
expected customer demand will be less engaged in executing coworker-directed behaviors.

Based on this, we hypothesize:

$\mathrm{H}_{6}$. Emphasizing the group-based component in a reward scheme makes (a) the effect of an FLE's expected customer demand on coworker-directed behaviors weaker and (b) the effect of an FLE's team identification on customer-directed behaviors stronger.

\section{METHOD}

\section{Research Context and Data Collection}

We gathered a unique, multisource (survey and objective) dataset from a global ICT company which operates in several countries and is representative of typical B2B, FLE contexts. In this company, customer interactions are multistep and relatively complex, and relational rather than transactional, by servicing approximately 500 business customers in sectors such as finance, the chemical industry, and logistics. Before data collection, we conducted 29 in-depth interviews with three executive managers, ten managers, five support staff, and eleven FLEs to become familiar with the setting, and to ensure that our survey fit the company's context. During the study's duration, the company transitioned to a product-service systems approach in which ICT product solutions are complemented with innovative, cloudbased service solutions. This study focusses on these new product-service solutions.

We collected data from three sources at different points in time. First, we asked 258 FLEs, organized into 32 work groups, to complete a questionnaire. After two reminders, sent over a three-week period, we received 180 responses from the FLEs (a 69.8\% response rate). All units sampled featured at least three responding FLEs. Second, we obtained information regarding job experience, work group tenure, and the percentage of new clients from company databases. Third, six months after collecting the questionnaire data, we obtained an objective measure from company databases which reflects each FLE's performance for new productservice solutions. Consistent with previous studies examining FLE performance, we use the percentage of quota. It represents a strong measure of individual FLE performance because it captures measurable task performance output while accounting for environmental factors (e.g., 
Agnihotri et al. 2014). We tested for potential nonresponse bias by first dividing the sample into thirds based on response times. Note that we found no significant differences in mean responses between early and late responders. In addition, we compared respondents and nonrespondents and found no differences in performance, job experience, or work group tenure.

\section{Measures}

We assessed the constructs in our conceptual model with well-established scales and adjusted where necessary the wording to match the research context. The eight-factor confirmatory factor analysis revealed a good fit to the data $\left(\chi^{2}=723.197\right.$; d.f. $=532$; comparative fit index $=.94$; Tucker-Lewis fit index $=.93$; root mean error of approximation $=$ .045 ; standardized root mean square residual $=.053$ ). As we report in the Appendix, the multiitem measures have acceptable reliability (composite reliabilities $>.70$ ), factor loadings are, with some exceptions, above .70 , and regarding the discriminant validity for all measures, the average variance is greater than .50 and larger than the squared correlations. The maximum VIF of 2.57 is below the threshold value of 10 for all predictors (Hair et al. 2010), indicating that there are no multicollinearity issues. See Table 2 for descriptive statistics.

\section{[INSERT TABLE 2 ABOUT HERE]}

We measured helping coworkers — coworker-directed behavior — using five items adapted from the helping scale developed by Podsakoff, Ahearne, and McKenzie (1997). Helping coworkers is the most frequently studied form of OCB and a strong predictor of group and organizational performance (Podsakoff et al. 2000). We measured proactive sellingcustomer-directed behavior-for the newly introduced product-service solutions using five items based on the proactive behavior scales developed by De Jong and De Ruyter (2004) and Bateman and Crant (1993). Proactive selling is a focal aspect of the core selling tasks directed at customers and especially important in complex product-service environments (Van der Borgh, De Jong, and Nijssen 2017a). We measured customer- and coworker-directed behaviors

relative to the behaviors of other work group members ("Within group Y, I am..."). That is, we 
focus on relative levels of customer- and coworker-directed behavior within the work group. Furthermore, we relied on self-rated measures because only FLEs themselves are aware of their specific actions which make them engage in a particular behavior. We measured each FLE's work group identification using the four-item scale from Van der Vegt and colleagues (2003). Regarding expected customer demand for the product-service combinations, we adapted a scale developed by Wieseke, Homburg, and Lee (2008), and expanded the original scale to four items to cover the most important performance metrics, namely, order intake, volume, revenue, profit, used to assess expectations of customer demand. FLEs categorically rated their primary source for information. We focused on the following three sources: internal business team, work group members, and the information system. FLEs' perceptions of work group-based rewards were assessed using a four-item scale adapted from Wei and Atuahene-Gima (2009).

We included several control variables for correct model estimation. First, we considered several background variables. Consistent with previous research (e.g., Ahearne et al. 2010), we obtained details about the FLE's job experience and work group tenure from company databases. We also controlled for organizational identification, measured using Mael and Ashforth's (1992) six-item scale, because inclusion of this measure accounts for a person's extra motivation to engage in customer- and coworker-directed behaviors. We operationalized each FLE's perceived work group efficacy using a four-item scale from De Jong et al. (2006) to control for perceptions of task instrumentality of the work group. Task autonomy was adapted from De Jong, De Ruyter, and Lemmink's (2004) scale. Finally, the percentage of product-service solutions sold to new clients served as a customer portfolio-specific element.

\section{Multilevel Considerations}

Given the nested structure of our dataset (i.e., FLEs were nested within units), responses from FLEs from the same unit may be interdependent. Therefore, we first assessed whether we should explicitly account for multiple levels in our analyses by examining the intraclass correlation coefficients (ICC) and corresponding design effects for the variables in our model. 
Results indicated that the ICCs range from .034 to .189. As small ICC values (e.g., .05) can already lead to considerable bias in the results when the dependence of observations is not controlled for (Cohen et al. 2003, p. 538), the ICC values are of sufficient size to warrant a multilevel approach. Also, results from Satorra and Muthen's (1995) procedure suggest that a multilevel structure should not be ignored as design effects approached the threshold of two.

\section{Endogeneity Considerations}

The effect of work group identification on helping coworkers may be spurious because common unobserved factors (e.g., team-level factors) may influence both work group identification and helping coworkers. For example, salespeople may be allocated to a work group based on their similarity with other coworkers, leading to issues regarding selection bias. Finally, it is possible that helping influences work group identification. These situations of "endogeneity" lead to violations of the required assumptions in estimating the parameters. As such, we tested for various sources of endogeneity.

First, to test for endogeneity due to an omission of important team-level (Level 2) fixed effects, which can produce inconsistent estimates for the individual-level (Level 1) predictors, we conducted a Hausman test (1978). In line with the suggestion made by Antonakis et al. (2010), we ran a model in which work group identification was group-mean centered at Level1 - and no other predictors or covariates were entered into the analysis - and compared the resulting coefficient $(\mathrm{B}=.351, \mathrm{p}<.000$; s.e. $=.076)$ with the one obtained from a model in which work group identification was grand-mean centered $(B=.272, p<.001 ;$ s.e. $=.052)$. The Hausman test was not significant $(\mathrm{z}=.82, \mathrm{p}>.10)$, thus alleviating concerns about endogeneity in our results. We also included the mean of work group identification as a covariate in our model to ensure correct estimation (Antonakis et al. 2010).

Second, we adopted Garen's (1984) control function procedure to correct for possible endogeneity in our analyses. First, we regressed work group identification on a set of predictors to obtain the structural residual term $(\hat{\varepsilon})$, in which we used collective work group identification 
prevalence (CWGIP) within each of the four departments as our primary predictor (cf. Germann, Ebbes, and Grewal 2015). CWGIP is the average value of group-mean centered perceptions of collective work group identification for each department, that is, the referent of the items is the group instead of the individual. This scale was adopted from Van der Vegt and Bunderson (2005). The relevance of this predictor rests on two premises. First, we argue that focal FLEs face similar conditions as peers in other groups within the same department as they execute similar tasks and as such engage in similar levels of helping. Moreover, we assert that the managerial orientations of the departmental leaders are comparable across the work groups. Thus, similar task conditions and similarity in managerial orientations should make the instrument relevant, that is, the relevance criterion. Second, we also argue that the predictor meets the criteria for the exclusion criterion, that is, the exogeneity condition, namely, why it is uncorrelated with the omitted variables affecting the helping behavior of salespeople. We argue that workgroup members cannot easily observe helping behaviors exhibited by coworkers in other workgroups. Since we examine field FLEs, these employees only understand the true level of helping when they directly interact with coworkers by receiving help from or providing help to them. Furthermore, when individuals do receive information about other groups, this information is often biased (e.g., only successes are shared) or perceived as unreliable (e.g., success is attributed to luck). As such, there is no direct motivation to change individual helping behavior toward coworkers within one's workgroup.

Following Antonakis et al. (2010), we also included other predictors to (i) prevent misspecification due to a possible weak instrument and (ii) enable the overidentification test to be conducted. Specifically, we included past performance, work group size, the age of the focal FLE, mean collective work group identification, and group-mean centered, collective work group identification. We then calculated the interaction term $(\hat{\varepsilon} \times W I D)$ and $(W I D \times W I D)$ to allow for the modeling of unobserved heterogeneity over the range of values of our endogenous variable, work group identification (WID). Finally, we added these three variables 
to our model to obtain consistent estimates. The multivariate F-test in the model with work group identification as an endogenous variable revealed that the instruments were sufficiently strong, with an F-value of 20.420 (d.f. $1=6$; d.f. $2=163 ; p<.001)$. The Sargan test showed that the exclusion criterion was satisfied $\left(\chi^{2}=1.632\right.$, d.f. $\left.=5, p=.897\right)$. The Durbin (and Wu-Hausman) test cannot reject the null hypothesis of no systematic differences in coefficients between a model which corrects for endogeneity and a model that does not $\left(\chi^{2}=.034\right.$, d.f. $\left.=1, p=.854\right)$. In short, the results of these analyses provide sufficient confidence that our results are robust and reliable.

\section{Model Specification}

We examined FLEs' engagement in customer- and coworker-directed behaviors using a dyadic framework (e.g., Menguc et al. 2016). As such, we were forced to take a two-step analytical approach to analyze our full model (see Kraus et al. 2015). In the first step, we analyzed, with a multilevel multivariate regression model, each antecedent's relative impact on the FLEs' customer- and coworker-directed behaviors as well as the moderating effect of group-based rewards. The multivariate model enabled the two dependent variables to be correlated and can therefore more effectively control for type I errors, often increasing power when compared with a series of univariate statistical tests. The multivariate multilevel model consists of a system of two interrelated sub-models of coworker-directed behaviors (i.e., helping behaviors) and customer-directed behaviors (i.e., proactive selling) and is specified as:

$$
\begin{aligned}
\mathrm{BEH}_{\mathrm{hij}}= & \mathrm{b}_{\mathrm{h} 0 \mathrm{j}}+\mathrm{b}_{\mathrm{h} 1 \mathrm{j}} \mathrm{ECD}_{\mathrm{ij}}+\mathrm{b}_{\mathrm{h} 2 \mathrm{j}} \mathrm{WID}_{\mathrm{ij}}+\mathrm{b}_{\mathrm{h} 3 \mathrm{j}} \mathrm{GBR}_{\mathrm{ij}}+\mathrm{b}_{\mathrm{h} 4 \mathrm{j}}\left(\mathrm{ECD}_{\mathrm{ij}} \times \mathrm{GBR}_{\mathrm{ij}}\right)_{\mathrm{ij}}+ \\
& \mathrm{b}_{\mathrm{h} 5 \mathrm{j}}\left(\mathrm{WID}_{\mathrm{ij}} \times \mathrm{GBR}_{\mathrm{ij}}\right)_{\mathrm{ij}}+\mathrm{b}_{\mathrm{h} 6 \mathrm{j}} \mathrm{INFS}_{\mathrm{ij}}+\mathrm{b}_{\mathrm{h} 7 \mathrm{j}} \mathrm{INFW}_{\mathrm{ij}}+\mathrm{b}_{\mathrm{h} 8 \mathrm{j}} \mathrm{EXP}_{\mathrm{ij}}+\mathrm{b}_{\mathrm{h} 9 \mathrm{j}} \mathrm{WGT}_{\mathrm{ij}}+ \\
& \mathrm{b}_{\mathrm{h} 10 \mathrm{j}} \mathrm{AUT}_{\mathrm{ij}}+\mathrm{b}_{\mathrm{h} 1 \mathrm{j} \mathrm{OID}_{\mathrm{ij}}}+\mathrm{b}_{\mathrm{h} 12 \mathrm{j}} \mathrm{WGT}_{\mathrm{ij}}+\mathrm{b}_{\mathrm{h} 13 \mathrm{j}} \mathrm{PNC}_{\mathrm{ij}}+\mathrm{b}_{\mathrm{h} 2 \mathrm{j}} \mathrm{WID}_{\mathrm{j}}+\mathrm{b}_{\mathrm{h} 15 \mathrm{j}} \hat{\varepsilon}_{\mathrm{ij}}+ \\
& \mathrm{b}_{\mathrm{h} 16 \mathrm{j}}\left(\hat{\varepsilon}_{\mathrm{ij}} \times \mathrm{WID}_{\mathrm{ij}}\right)_{\mathrm{ij}} \mathrm{b}_{\mathrm{h} 17 \mathrm{j}}\left(W I D_{\mathrm{ij}} \times \mathrm{WID}_{\mathrm{ij}}\right)_{\mathrm{ij}}+\mathrm{u}_{\mathrm{h} 0 \mathrm{j}}+\varepsilon_{\mathrm{h} 0 \mathrm{ij}}
\end{aligned}
$$

where $\mathrm{h}=1$ is customer-directed behaviors, $\mathrm{h}=2$ is coworker-directed behaviors, $\mathrm{i}$ is individual FLEs, $\mathrm{j}$ is work groups, BEH is customer-directed or coworker-directed behavior, ECD is the salesperson's expected customer demand, WID is work group identification, GBR is work group-based rewards, INFS is information from the information system, INFW is information from work group members, EXP is job experience, WGT is work group tenure, 
AUT is task autonomy, OID is organizational identification, WGE is perceived work group efficacy, PNC is the percentage of new clients, and $\hat{\varepsilon}$ is the structural residual term. The individual-level error term $\varepsilon_{\mathrm{h} 0 \mathrm{ij}} \sim \mathrm{N}(0, \sigma 2)$, and $\mathrm{u}_{\mathrm{h} 0 \mathrm{j}}$ denotes group-specific variances. Furthermore, $b_{\mathrm{h} 0 \mathrm{j}}$ is a random coefficient (i.e., intercept) which captures individual-specific unobserved heterogeneity within groups and as such, $\beta_{\mathrm{h} 0 \mathrm{j}}$ provides a mean value for the group effect and accounts for group-specific variances $\left(\mathrm{u}_{\mathrm{h} 0 \mathrm{j}}\right)$.

The second step involved the analysis of the outcomes for (im)balance between customer- and coworker-directed behaviors using a response surface analysis. The full multilevel model is:

$$
\begin{aligned}
& \operatorname{PERF}_{i j}=b_{0 j}+b_{1 j} C W B_{i j}+b \beta_{2 j} C U U B_{i j}+b_{3 j}\left(C W B_{i j} \times C W B_{i j}\right)_{i j}+b_{4 j}\left(C U B_{i j} \times\right. \\
& \left.\mathrm{CWB}_{\mathrm{ij}}\right)_{\mathrm{ij}}+\mathrm{b}_{5 \mathrm{j}}\left(\mathrm{CUB}_{\mathrm{ij}} \times \mathrm{CUB}_{\mathrm{ij}}\right)_{\mathrm{ij}}+\mathrm{b}_{6 \mathrm{j}} \mathrm{INFS}_{\mathrm{ij}}+\mathrm{b}_{7 \mathrm{j}} \mathrm{INFW}_{\mathrm{ij}}+\mathrm{b}_{8 \mathrm{j}}\left(\mathrm{CWB}_{\mathrm{ij}} \times\right. \\
& \left.\operatorname{INFS}_{\mathrm{ij}}\right)_{\mathrm{ij}}+\mathrm{b}_{9 \mathrm{j}}\left(\mathrm{CUB}_{\mathrm{ij}} \times \mathrm{INFS}_{\mathrm{ij}}\right)_{\mathrm{ij}}+\mathrm{b}_{10 \mathrm{j}}\left(\mathrm{CWB}_{\mathrm{ij}} \times \mathrm{CWB}_{\mathrm{ij}} \times \mathrm{INFS}_{\mathrm{ij}}\right)_{\mathrm{ij}}+
\end{aligned}
$$

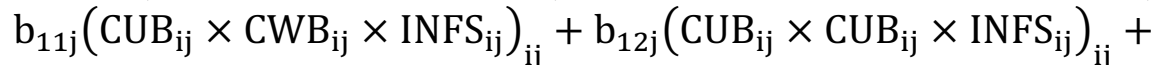

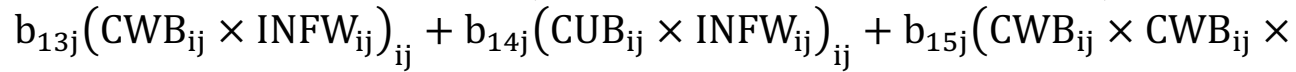

$$
\begin{aligned}
& \left.\mathrm{INFW}_{\mathrm{ij}}\right)_{\mathrm{ij}}+\mathrm{b}_{16 \mathrm{j}}\left(\mathrm{CUB}_{\mathrm{ij}} \times \mathrm{CWB}_{\mathrm{ij}} \times \mathrm{INFW}_{\mathrm{ij}}\right)_{\mathrm{ij}}+\mathrm{b}_{17 \mathrm{j}}\left(\mathrm{CUB}_{\mathrm{ij}} \times \mathrm{CUB}_{\mathrm{ij}} \times\right. \\
& \text { INFW } \left._{i j}\right)_{i j}+b_{18 j} \text { EXP }_{i j}+b_{19 j} W T_{i j}+b_{20 j} \text { PNC }_{i j}+u_{0 j}+\varepsilon_{0 i j} \text {, }
\end{aligned}
$$

where PERF is FLE performance, CWB is coworker-directed behaviors, and CUB is customer-directed behaviors.

\section{Sample Considerations}

Our test of the conceptual model relies on a multilevel, multisource dataset with lagged FLE performance from a single company. Although collecting such data in B2B settings is difficult and reliance on one company and setting reduces the potential confounding effects of company- or industry-level variables, this approach also may limit the generalizability of our findings to other domains and settings. In our quest to demonstrate the suitability of our sample and hence, the generalizability of our findings, we triangulated our outcomes with previous studies on customer- and coworker-directed behaviors. Specifically, we compiled a metaanalytic overview of the relationship between coworker-directed behaviors, customer-directed behaviors, and individual job performance research. We present this overview in Table 3 , 
which shows that our results closely mirror and replicate the stream of related work, thereby providing some evidence of the suitability and generalizability of our work.

[INSERT TABLE 3 ABOUT HERE]

\section{RESULTS}

\section{Consequences of Customer-Coworker (Im)Balance}

To test our hypotheses regarding the consequences of FLE balance and imbalance, we followed previous studies using response surface modeling (e.g., Menguc et al. 2016). We plotted a three-dimensional surface plot displaying the relationship between customer- and coworker-directed behaviors to facilitate the interpretation of these analyses. Consistent with previous studies, we highlight the cross-sectional plot lines for balance and imbalance used to support each main effect hypothesis $\left(\mathrm{H}_{1}\right.$ and $\left.\mathrm{H}_{2}\right)$.

$\mathrm{H}_{1}$ posits that increasing FLE balance is associated with higher levels of FLE performance. Table 4 indicates that the surface analysis for the performance along the balance line was nonsignificant $\left(b_{1}+b_{2}=-.001, p>.05\right)$. Similarly, the balance curvature was also nonsignificant $\left(b_{3}+b_{4}+b_{5}=.082, p>.05\right)$. As such, $H_{1}$ is not supported.

\section{[INSERT TABLE 4 ABOUT HERE]}

Furthermore, $\mathrm{H}_{2}$ posits that an imbalance between customer- and coworker-directed behaviors relates negatively to FLE performance. The results revealed a significant negative curvature $\left(b_{3}-b_{4}+b_{5}=-.445, p<.01\right)$ and significant slope along the imbalance line $\left(b_{1}-b_{2}=\right.$ $-.475, \mathrm{p}<.01$ ), providing support for $\mathrm{H}_{2}$. As Figure 2 illustrates, there is an inverted U-shape along the imbalance line, with a larger negative effect on FLE performance when the FLE's emphasis is on coworker-directed behaviors.

\section{[INSERT FIGURE 2 ABOUT HERE]}

\section{Moderating Effect of Primary Information Sources Consulted}

We also found that the FLE balance line was insignificant when information was obtained primarily from the internal business team $\left(b_{1}+b_{2}=.125, p>.05\right)$ or information 
system $\left(b_{1}+b_{2}+b_{8}+b_{9}=.116, p>.05\right)$, but became positive and significant when help was sought from coworkers $\left(\mathrm{b}_{1}+\mathrm{b}_{2}+\mathrm{b}_{13}+\mathrm{b}_{14}=.384, \mathrm{p}<.05\right)$, supporting $\mathrm{H}_{3 \mathrm{a}}$. As Figure 3, Panel A further illustrates, FLEs only benefitted from coworkers as a source of information when they themselves exhibited an increased level of customer- and coworker-directed behaviors. At low levels of engagement (i.e., negative balance), sourcing for information among coworkers was not effective and even led to lower FLE performance. This effect was not observed for unbiased sources of information (i.e., information system; internal business team).

\section{[INSERT FIGURE 3 ABOUT HERE]}

In support of $\mathrm{H}_{3 b}$, the results demonstrate a significant dampening effect for the imbalance line when FLEs sourced information primarily within the work group $\left(b_{1}-b_{2}+b_{13}-\right.$ $\left.b_{14}=-.301, p>.05\right)$, whereas the negative relationship became more negative when information was sourced from the information system $\left(b_{1}-b_{2}+b_{8}-b_{9}=-.656, p<.05\right)$ and the internal business team $\left(b_{1}-b_{2}=-.786, p<.05\right)$. Moreover, the results also support a significant dampening effect for the imbalance curvature when FLEs sourced information within the work group $\left(b_{3}-b_{4}+b_{5}+b_{15}-b_{16}+b_{17}=-.145, p>.05\right)$ or from the information system $\left(b_{3}-b_{4}+b_{5}\right.$ $\left.+b_{10}-b_{11}+b_{12}=-.019, p>.05\right)$, whereas the negative curvature became more negative when information was sourced from the internal business team $\left(b_{3}-b_{4}+b_{5}=-.610, p<.05\right)$.

In sum, as Figure 3, Panel B reveals, these results support $\mathrm{H}_{3 \mathrm{~b}}$, as indicated by the weakened effect of imbalance, through either overemphasizing or underemphasizing coworkerdirected behavior, when FLEs mainly sourced information within their work group. Interestingly, when FLEs sourced information mainly from the information system, they benefitted from underemphasizing coworker-directed behavior, that is, the emphasis is on customer-directed behaviors, whereas FLE performance decreased when they overestimated coworker-directed behavior. Finally, FLEs were unable to counter the negative effects of imbalance via information sourced from the internal business team, suggesting the importance of coworkers for FLE performance when delivering product-service solutions. 


\section{Drivers of Customer-Coworker (Im)Balance}

Table 5 lists the results for the antecedents of customer- and coworker-directed behaviors. The main effects model reveals that the antecedents differentially affected each outcome. Expected customer demand had a positive significant effect only on customerdirected behaviors $\left(\mathrm{b}_{11}=.092, p<.05\right)$, while FLE work group identification had a positive significant effect only on coworker-directed behaviors $\left(\mathrm{b}_{22}=.185, p<.01\right)$. We used the BIEMS software (Mulder et al. 2009) to formally test $\mathrm{H}_{4}-\mathrm{H}_{5}$, the so-called informative hypotheses in which (in)equalities $\left(=,<\right.$, or $>$ ) between $\beta_{\mathrm{jh}}{ }^{\prime} s$ were hypothesized. In contrast to traditional approaches, this approach can account for the direction of a hypothesis while including other variables as covariates. The software uses the Bayes Factor (BF) as a selection criterion when testing inequality constrained models (Mulder et al. 2009). The BF can be interpreted as the amount of evidence in favor of the constrained model $\mathrm{M}_{\mathrm{q}}$ against the unconstrained, or most complex, model $\mathrm{M}_{\mathrm{q} 0}$ (Mulder et al. 2009). When $\mathrm{BF}>1$, the odds are in favor of model $\mathrm{M}_{\mathrm{q}}$. To test $\mathrm{H}_{4}$, we imposed a constraint on the model for expected customer demand $\left(b_{11}>b_{21}\right)$. The analysis revealed that $b_{11}(.105)>b_{21}(.052)$, as indicated by a BF of 1.57, supports $\mathrm{H}_{4}$. As such, we can conclude that expected customer demand affects customerdirected behaviors more than coworker-directed behaviors. Likewise, the analysis demonstrates that work group identification coefficients are unlikely to be equivalent to customer-directed behaviors and coworker-directed behaviors $\left(\mathrm{b}_{22}[.175]>\mathrm{b}_{12}[.080]\right.$; $\left.\mathrm{BF}=1.98\right)$, supporting $\mathrm{H}_{5}$.

\section{[INSERT TABLE 5 ABOUT HERE]}

\section{Moderating Effect of Work Group-Based Rewards}

$\mathrm{H}_{6 \mathrm{a}-\mathrm{b}}$ posit that more emphasis on the group-based component may reduce customercoworker balance. We added group-based rewards to our model as an interaction variable to test this claim. Including the interaction coefficients significantly increased the model's explanatory power $\left(\chi^{2}(4)=10.759, p<.05\right)$, providing justification for the full model. The main effects of expected customer demand on customer-directed behaviors and work group 
identification on coworker-directed behaviors remained significant and positive $\left(\mathrm{b}_{11}=.105, p<\right.$ $\left..05 ; \mathrm{b}_{22}=.175, p<.05\right)$. Similarly, the effect of expected customer demand on coworkerdirected behaviors and the effect of work group identification on customer-directed behaviors remained nonsignificant $\left(\mathrm{b}_{12}=.080, p>.05 ; \mathrm{b}_{21}=.052, p>.05\right)$. However, in predicting coworker-directed behaviors, the interaction between expected customer demand and groupbased rewards was significant and negative $\left(\mathrm{b}_{24}=-.090, p<.05\right)$. In predicting customerdirected behaviors, the interaction between work group identification and group-based rewards was significant and positive $\left(\mathrm{b}_{15}=.099, p<.05\right)$. These findings support $\mathrm{H}_{6 \mathrm{a}-\mathrm{b}}$. Figure 4 illustrates that, consistent with our hypotheses, more emphasis on group-based rewards makes the effect of an FLE's expected customer demand on coworker-directed behaviors turn negative (Figure 4, Panel A), while the effect of an FLE's work group identification on customer-directed behavior becomes positive (Figure 4, Panel B). These findings suggest that under such conditions, a large customer-coworker imbalance is likely to occur.

\section{[INSERT FIGURE 4 ABOUT HERE]}

\section{DISCUSSION}

Although firms largely rely on FLEs' boundary-spanning role behaviors in obtaining performance targets for product-service offerings, our understanding of FLEs' role-balancing behaviors is still limited. This study provides important insight into when and how companies benefit most from these role-balancing behaviors in a product-service system context. We offer new understandings of antecedents and outcomes of customer-coworker balance.

\section{Research Implications}

Importance of an inclusive FLE behavior model. Previous FLE research has focused either on customer- or coworker-directed behaviors as relatively independent activities (e.g., Rapp, Bachrach, and Rapp 2013). Our approach contributes to this research in one significant way: We integrate both types of FLE performance behaviors in one model and focus on customer-coworker (im)balance. Balancing customer-coworker behaviors is critical but 
difficult in loosely knit, group-based frontline settings (Grant and Patil 2012), because on the one hand, the FLE must be loyal to his or her coworkers, while on the other hand, he or she wants to serve customers competently. Using response surface modeling, we examined the complex matter of customer-coworker (im)balance and demonstrated its distinct linear and curvilinear effect on FLE performance. This approach can easily be extended to other work settings.

Impact of customer-coworker (im)balance on FLE performance. Our results reveal that balance does not harm FLE performance in a product-service context. Surprisingly, the results demonstrate that negative and positive states of customer-coworker balance do not significantly differ in their effect, which suggests the existence of contingencies. Adopting an information acquisition perspective, our research indicates that when the focal FLE relies primarily on coworkers within their work group for information, a positive relationship between balance and FLE performance is present. This finding can be explained by the type of information source; coworkers are both a personal and biased information source. When there is a negative balance, that is, low emphasis on both behavioral domains, the focal FLE does not benefit from seeking help regarding product-service solutions from coworkers. Possibly, low engagement leads to low levels of reciprocity of useful information by coworkers. An alternative explanation of the nonsignificant main effect of role balance may be whether FLEs engage in hard versus smart working styles (e.g., Sujan, Weitz, and Kumar 1994). The degree to which FLEs can work smart determines their relative level of engagement in one or both role domains and how this affects their performance. ${ }^{1}$ We urge future research on this topic.

Higher levels of customer-coworker imbalance result in lower levels of FLE performance. We empirically substantiate the sociotechnical systems theory perspective (Pasmore et al. 1982; Trist et al. 2013), which contends that the most effective organizations are those in which the social- and task-related systems are integrated and supportive of one another (Emery 1959), by testing this theory in the organizational frontline and demonstrating 
that individual FLEs who overemphasize either their core task (i.e., serving customers), or their social task (i.e., helping coworkers), suffer deteriorated performance. This finding implies that for complex settings in which FLEs provide customized product-service solutions, it becomes increasingly difficult to behave as "lone wolves". Overemphasizing coworker-directed behaviors is especially harmful. Neglecting one's core task may lead to a lack of customerspecific knowledge necessary to identify and overcome idiosyncratic customer problems.

The effects of customer-coworker imbalance can be detrimental to FLE performance. Yet, our study reveals that relying on specific information sources can cancel out the negative impact of imbalance. As Figure 3, Panel B illustrates, when the focal FLE relies on coworkers in their work group for information, he or she is, on average, performing well, irrespective of the direction of imbalance. Interestingly, when an FLE relies primarily on the information system for guidance, the negative effect of underemphasizing coworker-directed behaviors is canceled out and even becomes positive. Apparently, the general information and best practices available in the information system can substitute low levels of coworker-directed behaviors. This finding provides evidence for the importance of an information system in FLE performance. Finally, our results reveal that information from the internal business team cannot counter the negative effect of customer-coworker imbalance. The type of information provided by employees from the internal business team with different functional backgrounds, for example, finance, marketing, operations, cannot substitute FLE-specific intelligence.

Antecedents to customer-coworker imbalance. Because imbalance between customerand coworker-directed roles can cause suboptimal outcomes, scholars have called for a better understanding of the drivers of FLE engagement in such behaviors (Plouffe et al. 2016). In response, we demonstrate that expected customer demand leads to underemphasizing customer-directed behaviors, whereas work group identification leads to overemphasizing coworker-directed behaviors. Although research has demonstrated that both identification and expected customer demand are typically associated with increased FLE performance (e.g., 
Wieseke, Homburg, and Lee 2008), our results reveal that their effect can lead to imbalance in the boundary-spanning role, thereby limiting the effect on FLE performance (see Figure 4, Panels A and B). Without examining both customer- and coworker-directed behaviors in one model, it is impossible to determine how balance and imbalance occurs. Furthermore, our findings reveal that managers can counter customer-coworker imbalance via the control system. By placing greater emphasis on the individual component - relative to the group component - managers can reduce the level of imbalance. At first, this finding may seem counterintuitive as group-based components in incentive systems are often used to balance engagement in task- and contextual (i.e., group)-directed behaviors (Lim and Chen 2014). However, the results support our rationale that group-based incentives reduce the instrumentality, that is, perceived control regarding a desired outcome, which therefore makes FLEs focus more on their task accomplishment.

\section{Managerial Implications}

Our study provides guidelines for managers on how to motivate their FLEs to balance effectively customer- and coworker-directed behaviors when designing and delivering productservice systems and curtail the negative effects of imbalance.

Managing drivers of imbalance. While previous research has indicated the importance of expected customer demand and work group identification, our study indicates that these drivers also have undesired effects on FLE engagement in customer- and coworker-directed behaviors. Specifically, our results demonstrate that high expectancies of customer demand lead to underemphasizing coworker-directed behaviors. In contrast, high identification with the work group leads to a neglect of customer-directed behaviors. Additionally, our findings show that managers can curb unwanted imbalance situations by emphasizing the individual over the group-based component in their incentive scheme.

The findings also provide useful insights into how to manage undesired effects of FLEs handling high customer demand or those with high levels of work group identification. 
Specifically, managers should try to recognize how their subordinates perceive the customer's demand and how FLEs are involved in their work group. Symptoms of imbalance are present when FLEs experience high customer demands while displaying a low commitment to the work group, or vice versa. In such instances, we advise managers to emphasize both the importance of the individual's role and task within the work group with that of the customer's perspective. This approach helps ensure that FLEs feel self-control in obtaining targets but also makes clear how individual FLE performance adds to the work group. In addition, the manager may stress the competence of the work group, provide more task autonomy, or build greater organizational identification as these mechanisms provide an extra incentive for FLEs to help coworkers and serve customers (see Table 5).

The balancing approach to manage FLE behaviors. Firms are increasingly recognizing the importance of coworker-directed behaviors at the frontline as a way to share best practices and improve FLE performance (CSO Insights 2014). By monitoring how much FLEs engage in both activities, managers can measure role imbalance and consequently, improve job performance, job satisfaction, and on-the-job learning. Despite its importance, firms have mainly focused on facilitating customer-directed behaviors, for example, aligning sales tools to customer behaviors, revising channel strategies, and improving sales representatives' access to information (CSO Insights 2014). Our findings reveal that both behaviors are often not aligned or at a low-to-medium level (pairwise correlation .6), indicating the potential for improvement. To foster positive role balance, managers may need to monitor how many contributions an FLE is making toward coworkers, for example, by attendance at work group meetings or logging data in the information system. Managers can compare these data with other FLEs in the work group to identify potential imbalances and guide reps toward more balance.

Using information sources as leverage. The primary information source consulted by the focal FLE also has important implications for the effectiveness of their role engagement. First, we stress the importance of distinguishing between personal or impersonal and biased or 
unbiased sources. Our findings reveal that biased and personal information sources, that is, coworkers, have the largest impact on the relationship between customer-coworker (im)balance and FLE performance. When subordinates rely primarily on coworkers for help, managers should ensure that these FLEs exert high levels of engagement in at least one role domain. Furthermore, when a subordinate is unwilling or unable to participate in the work group, the manager should stress the importance of using the information system. In this case, it is important to track how often an FLE consulted the information system for help. This approach, however, requires companies to possess an excellent information system. Finally, when FLEs rely on the internal business team for help, it is crucial that managers guide these FLEs toward customer-coworker balance because imbalance leads to considerable impediments in FLE performance, which cannot be substituted with information from the internal business team.

\section{Limitations and Future Research}

This study primarily examines FLE-specific perceptions which cause perceptions of balance or imbalance. Further research could benefit from investigating how these perceptions are formed. Research on stakeholder theory (Plouffe et al. 2016) can provide a starting point. Specifically, future research should examine how perceptions of behavior differ from actual behavior and how these biases may explain FLE performance. Although the information in Table 4 suggests that the findings presented here are consistent with prior research, a more systematic replication in other firms or industries with larger samples could help extend our understanding of and generalizability of the current findings. In our study, we focus on work group identification and expected customer demand as drivers of customer-coworker (im)balance. Other studies could investigate other variables linked to, for instance, other actors in the role set, for example, considering multiple actors in the decision-making unit. Finally, many frontline settings involve teams in which customer investments are collective. Future studies should adopt a multilevel model in which customer- and coworker-directed behaviors are compared at both the individual and team levels. Given the large investments in team-based 
selling and account management, we believe that investigating team-level behavioral processes is a critical area for further research. 


\section{References}

Agneessens, F. and R. Wittek (2011), "Where Do Intra-Organizational Advice Relations Come From," The role of informal status and social capital in social exchange Social Networks, 34, 333-345.

Agnihotri, Raj, Michael Krush, and Rakesh K. Singh (2012), "Understanding the mechanism linking interpersonal traits to pro-social behaviors among salespeople: Lessons from India," Journal of Business \& Industrial Marketing, 27 (3), 211-227.

, Adam A. Rapp, James 'Mick' Andzulis, and Colin B. Gabler (2014), "Examining the Drivers and Performance Implications of Boundary Spanner Creativity," Journal of Service Research, 17 (2), 164-81.

Ahearne, Michael, Adam Rapp, Douglas E. Hughes, and Rupinder Jindal (2010), "Managing sales force product perceptions and control systems in the success of new product introductions," Journal of Marketing Research, 47 (4), 764-776.

Allen, Natalie J. and John P. Meyer (2000), "Construct validation in organizational behavior research: The case of organizational commitment," in Problems and solutions in human assessment, Springer, 285-314.

Antonakis, John, Samuel Bendahan, Philippe Jacquart, and Rafael Lalive (2010), "On making causal claims: A review and recommendations," The Leadership Quarterly, 21 (6), 1086-1120.

Aryee, Samuel, Ekkirala S. Srinivas, and Hwee Hoon Tan (2005), "Rhythms of life: antecedents and outcomes of work-family balance in employed parents.," Journal of applied psychology, 90 (1), 132.

Bakker, Arnold B., Evangelia Demerouti, and Willem Verbeke (2004), "Using the job demands-resources model to predict burnout and performance," Human Resource Management 43 (1), 83-104.

Barnett, Rosalind Chait and Janet Shibley Hyde (2001), "Women, men, work, and family.," American psychologist, 56 (10), 781.

Bateman, Thomas S. and J. Michael Crant (1993), "The proactive component of organizational behavior: A measure and correlates," Journal of organizational behavior, 14 (2), 103 118.

Bergeron, Diane M. (2007), "The potential paradox of organizational citizenship behavior: Good citizens at what cost?," Academy of Management Review, 32 (4), 1078-1095.

Bettencourt, Lance A. and Stephen W. Brown (1997), "Contact employees: Relationships among workplace fairness, job satisfaction and prosocial service behaviors," Journal of retailing, 73 (1), 39-61.

Biddle, Bruce J. (2013), Role theory: Expectations, identities, and behaviors, Academic Press.

Blader, Steven L. and Tom R. Tyler (2009), "Testing and extending the group engagement model: Linkages between social identity, procedural justice, economic outcomes, and extrarole behavior.," Journal of applied psychology, 94 (2), 445.

Bolander, Willy, Cinthia B. Satornino, Douglas E. Hughes, and Gerald R. Ferris (2015), "Social Networks Within Sales Organizations: Their Development and Importance for Salesperson Performance," Journal of Marketing, 79 (6), 1-16.

Cheng, Jui-Chang and Chien-Yu Chen (2017), "Job resourcefulness, work engagement and prosocial service behaviors in the hospitality industry," International Journal of Contemporary Hospitality Management, 29 (10), 2668-2687.

Cohen, Aaron, Eli Ben-Tura, and Dana R. Vashdi (2012), "The relationship between social exchange variables, OCB, and performance: what happens when you consider group characteristics?," Personnel Review, 41 (6), 705-731.

Cohen, Jacob, Patricia Cohen, Stephen G. West, and Leona S. Aiken (2003), "Applied multiple correlation/regression analysis for the behavioral sciences," UK: Taylor \& Francis.

CSO Insights (2014), "2014 Sales Performance Optimization Study,” CSO Insights. 
De Jong, Ad and Ko De Ruyter (2004), “Adaptive versus proactive behavior in service recovery: the role of self-managing teams," Decision Sciences, 35 (3), 457-491. , and Jos Lemmink (2004), "Antecedents and consequences of the service climate in boundary-spanning self-managing service teams," Journal of Marketing, 68 (2), 18-35.

, and Martin Wetzels (2006), "Linking employee confidence to performance: A study of self-managing service teams," Journal of the Academy of Marketing Science, 34 (4), 576-587.

Deci, Edward L., Richard Koestner, and Richard M. Ryan (1999), "A meta-analytic review of experiments examining the effects of extrinsic rewards on intrinsic motivation.," Psychological bulletin, 125 (6), 627.

Emery, F. E. (1959), "Characteristics of socio-technical systems (Document No. 527)," London: Tavistock Institute of Human Relations.

Evanschitzky, Heiner, Christopher Groening, Vikas Mittal, and Maren Wunderlich (2011), "How employer and employee satisfaction affect customer satisfaction: An application to franchise services," Journal of Service Research, 14 (2), 136-148.

Frick, Jonathan and Mark Kovac (2017), "The Analytics of Sales Time Well Spent," Brief, .

Fu, Frank Q., Keith A. Richards, Douglas E. Hughes, and Eli Jones (2010), "Motivating salespeople to sell new products: The relative influence of attitudes, subjective norms, and self-efficacy," Journal of Marketing, 74 (6), 61-76.

Garen, John (1984), "The returns to schooling: A selectivity bias approach with a continuous choice variable," Econometrica: Journal of the Econometric Society, 1199-1218.

George, Jennifer M. (1991), "State or trait: Effects of positive mood on prosocial behaviors at work.," Journal of applied Psychology, 76 (2), 299.

Germann, Frank, Peter Ebbes, and Rajdeep Grewal (2015), "The chief marketing officer matters!," Journal of Marketing, 79 (3), 1-22.

Gonzalez, Gabriel R., Danny P. Claro, and Robert W. Palmatier (2014), "Synergistic effects of relationship managers' social networks on sales performance," Journal of marketing, 78 (1), 76-94.

Grant, Adam M. and Shefali V. Patil (2012), "Challenging the norm of self-interest: Minority influence and transitions to helping norms in work units," Academy of Management Review, 37 (4), 547-568.

Greenhaus, Jeffrey H., Karen M. Collins, and Jason D. Shaw (2003), "The relation between work-family balance and quality of life," Journal of vocational behavior, 63 (3), 510531.

Hair, Joseph F., WC Black, RE Anderson, and RJ Babin (2010), "Multivariate data analysis," Multivariate data analysis, 7.

Hausman, Jerry A. (1978), "Specification tests in econometrics," Econometrica: Journal of the econometric society, 1251-1271.

Katz, Daniel and Robert Louis Kahn (1978), "The social psychology of organizations."

Kelly, Scott W. and K. Douglas Hoffman (1997), "An investigation of positive affect, prosocial behaviors and service quality," Journal of Retailing, 73 (3), 407.

Kim, Hyun Jeong, Pimtong Tavitiyaman, and Woo Gon Kim (2009), "The effect of management commitment to service on employee service behaviors: The mediating role of job satisfaction," Journal of Hospitality \& Tourism Research, 33 (3), 369-390.

Kraus, Florian, Till Haumann, Michael Ahearne, and Jan Wieseke (2015), "When sales managers and salespeople disagree in the appreciation for their firm: The phenomenon of organizational identification tension," Journal of retailing, 91 (3), 486-515.

Langfred, Claus W. and Neta A. Moye (2004), "Effects of task autonomy on performance: an extended model considering motivational, informational, and structural mechanisms.," Journal of Applied Psychology, 89 (6), 934. 
Liao, Chenwei, Sandy J. Wayne, Robert C. Liden, and Jeremy D. Meuser (2017), "Idiosyncratic deals and individual effectiveness: The moderating role of leader-member exchange differentiation," The Leadership Quarterly, 28 (3), 438-450.

Lim, Noah and Hua Chen (2014), "When do group incentives for salespeople work?," Journal of Marketing Research, 51 (3), 320-334.

Locke, Edwin A., Ken G. Smith, Miriam Erez, Dong-Ok Chah, and Adam Schaffer (1994), "The effects of intra-individual goal conflict on performance," Journal of Management, 20 (1), 67-91.

MacKenzie, Scott B., Philip M. Podsakoff, and Michael Ahearne (1998), "Some possible antecedents and consequences of in-role and extra-role salesperson performance," The Journal of Marketing, 87-98.

, - — , and Richard Fetter (1991), "Organizational citizenship behavior and objective productivity as determinants of managerial evaluations of salespersons' performance," Organizational behavior and human decision processes, 50 (1), 123-150. evaluations of salesperson performance," The Journal of Marketing, 70-80.

,-- , and Julie Beth Paine (1999), "Do citizenship behaviors matter more for managers than for salespeople?," Journal of the Academy of Marketing Science, 27 (4), 396-410.

Madhavan, Ravindranath and Rajiv Grover (1998), "From embedded knowledge to embodied knowledge: New product development as knowledge management," The Journal of marketing, 1-12.

Mael, Fred and Blake E. Ashforth (1992), "Alumni and their alma mater: A partial test of the reformulated model of organizational identification," Journal of Organizational Behavior, 13 (2), 103-123.

Malhotra, Neeru and Anna-Lena Ackfeldt (2016), "Internal communication and prosocial service behaviors of front-line employees: Investigating mediating mechanisms," Journal of Business Research, 69 (10), 4132-4139.

Marks, Stephen R. and Shelley M. MacDermid (1996), "Multiple roles and the self: A theory of role balance," Journal of Marriage and the Family, 417-432.

Marshall, Greg W., William C. Moncrief, Felicia G. Lassk, and C. David Shepherd (2012), "Linking performance outcomes to salesperson organizational citizenship behavior in an industrial sales setting," Journal of Personal Selling \& Sales Management, 32 (4), 491501.

Mayer, David and Herbert M. Greenberg (2006), "What Makes a Good Salesman," Harvard Business Review, (accessed September 23, 2016), [available at https://hbr.org/2006/07/what-makes-a-good-salesman].

McAllister, Daniel J., Dishan Kamdar, Elizabeth Wolfe Morrison, and Daniel B. Turban (2007), "Disentangling role perceptions: how perceived role breadth, discretion, instrumentality, and efficacy relate to helping and taking charge.," Journal of Applied Psychology, 92 (5), 1200.

Menguc, Bulent, Seigyoung Auh, Constantine S. Katsikeas, and Yeon Sung Jung (2016), "When Does (Mis) Fit in Customer Orientation Matter for Frontline Employees' Job Satisfaction and Performance?," Journal of Marketing, 80 (1), 65-83.

Moriarty Jr, Rowland T. and Robert E. Spekman (1984), "An empirical investigation of the information sources used during the industrial buying process," Journal of Marketing Research, 137-147.

Mulder, Joris, Irene Klugkist, Rens van de Schoot, Wim HJ Meeus, Maarten Selfhout, and Herbert Hoijtink (2009), "Bayesian model selection of informative hypotheses for repeated measurements," Journal of Mathematical Psychology, 53 (6), 530-546. 
Mulki, Jay Prakash, Fernando Jaramillo, and Greg W. Marshall (2007), "Lone wolf tendencies and salesperson performance," Journal of Personal Selling \& Sales Management, 27 (1), $25-38$.

Müller, Johannes (2007), "Global exchange of knowledge and best-practices in Siemens building technologies with 'References@ SBT,"” in Knowledge Management: Innovation, Technology and Cultures, World Scientific, 55-64.

Muthén, Bengt O. and Albert Satorra (1995), "Technical aspects of Muthén's LISCOMP approach to estimation of latent variable relations with a comprehensive measurement model," Psychometrika, 60 (4), 489-503.

Netemeyer, Richard G., James S. Boles, Daryl O. McKee, and Robert McMurrian (1997), “An investigation into the antecedents of organizational citizenship behaviors in a personal selling context," The Journal of Marketing, 85-98. and James G. Maxham III (2007), "Employee versus supervisor ratings of performance in the retail customer service sector: Differences in predictive validity for customer outcomes," Journal of Retailing, 83 (1), 131-145.

Ostrom, Amy L., Mary Jo Bitner, Stephen W. Brown, Kevin A. Burkhard, Michael Goul, Vicki Smith-Daniels, Haluk Demirkan, and Elliot Rabinovich (2010), "Moving Forward and Making a Difference: Research Priorities for the Science of Service," Journal of Service Research, 13 (1), 4-36.

Pasmore, William, Carole Francis, Jeffrey Haldeman, and Abraham Shani (1982), "Sociotechnical systems: A North American reflection on empirical studies of the seventies," Human relations, 35 (12), 1179-1204.

Piercy, Nigel F., David W. Cravens, Nikala Lane, and Douglas W. Vorhies (2006), "Driving organizational citizenship behaviors and salesperson in-role behavior performance: The role of management control and perceived organizational support," Journal of the Academy of Marketing Science, 34 (2), 244-262.

Pitt, Leyland F., Michael T. Ewing, and Pierre R. Berthon (2002), "Proactive behavior and industrial salesforce performance," Industrial marketing management, 31 (8), 639-644.

Plouffe, Christopher R., Willy Bolander, Joseph A. Cote, and Bryan Hochstein (2016), "Does the Customer Matter Most? Exploring Strategic Frontline Employees' Influence of Customers, the Internal Business Team, and External Business Partners," Journal of Marketing, 80 (1), 106-123.

- and Yany Grégoire (2011), "Intraorganizational employee navigation and socially derived outcomes: Conceptualization, validation, and effects on overall performance," Personnel Psychology, 64 (3), 693-738.

Podsakoff, Philip M., Michael Ahearne, and Scott B. MacKenzie (1997), "Organizational citizenship behavior and the quantity and quality of work group performance.," Journal of Applied Psychology, 82 (2), 262.

- and Scott B. Mackenzie (1994), "Organizational citizenship behaviors and sales unit effectiveness," Journal of Marketing Research, 351-363.

—, Scott B. MacKenzie, Julie Beth Paine, and Daniel G. Bachrach (2000), "Organizational citizenship behaviors: A critical review of the theoretical and empirical literature and suggestions for future research," Journal of Management, 26 (3), 513-563.

Rapp, Adam A., Daniel G. Bachrach, and Tammy L. Rapp (2013), "The influence of time management skill on the curvilinear relationship between organizational citizenship behavior and task performance.," Journal of Applied Psychology, 98 (4), 668.

Raub, Steffen and Christopher Robert (2010), "Differential effects of empowering leadership on in-role and extra-role employee behaviors: Exploring the role of psychological empowerment and power values," Human Relations, 63 (11), 1743-1770.

Restubog, Simon Lloyd D., Prashant Bordia, and Robert L. Tang (2007), "Behavioural outcomes of psychological contract breach in a non-western culture: The moderating role of equity sensitivity," British Journal of Management, 18 (4), 376-386. 
Rodwell, John, John McWilliams, and Andre Gulyas (2017), "The impact of characteristics of nurses' relationships with their supervisor, engagement and trust, on performance behaviours and intent to quit," Journal of advanced nursing, 73 (1), 190-200.

Settoon, Randall P., Nathan Bennett, and Robert C. Liden (1996), "Social exchange in organizations: Perceived organizational support, leader-member exchange, and employee reciprocity.," Journal of applied psychology, 81 (3), 219.

Sujan, Harish, Barton A. Weitz, and Nirmalya Kumar (1994), "Learning orientation, working smart, and effective selling," The Journal of Marketing, 39-52.

Sumer, H. Canan and Patrick A. Knight (2001), "How do people with different attachment styles balance work and family? A personality perspective on work-family linkage.," Journal of Applied Psychology, 86 (4), 653.

Tamer Cavusgil, S., Roger J. Calantone, and Yushan Zhao (2003), "Tacit knowledge transfer and firm innovation capability," Journal of business \& industrial marketing, 18 (1), 6 21.

Trist, Eric L., Gurth W. Higgin, Hugh Murray, and Alex B. Pollock (2013), Organizational choice, Routledge.

Tyler, Tom R. and Steven L. Blader (2003), "The group engagement model: Procedural justice, social identity, and cooperative behavior," Personality and Social Psychology Review, 7 (4), 349-361.

Van der Borgh, Michel, Ad De Jong, and Edwin J. Nijssen (2017a), "Alternative mechanisms guiding salespersons' ambidextrous product selling," British Journal of Management, 28 (2), 331-53.

, — poor: The contingent role of common and unique position within the sales team," Industrial Marketing Management, Forthcoming.

Van der Vegt, Gerben S. and J. Stuart Bunderson (2005), "Learning and performance in multidisciplinary teams: The importance of collective team identification," Academy of management Journal, 48 (3), 532-547. , and Aad Oosterhof (2006), "Expertness diversity and interpersonal helping in teams: Why those who need the most help end up getting the least," Academy of Management Journal, 49 (5), 877-893.

—, Evert Van de Vliert, and Aad Oosterhof (2003), "Informational dissimilarity and organizational citizenship behavior: The role of intrateam interdependence and team identification," Academy of Management Journal, 46 (6), 715-727.

Verbeke, Willem, Bart Dietz, and Ernst Verwaal (2011), "Drivers of sales performance: a contemporary meta-analysis. Have salespeople become knowledge brokers?," Journal of the Academy of Marketing Science, 39 (3), 407-428.

Vilela, Belén Bande, José A. Varela González, and Pilar Fernández Ferrín (2008), "Personorganization fit, OCB and performance appraisal: Evidence from matched supervisorsalesperson data set in a Spanish context," Industrial Marketing Management, 37 (8), $1005-1019$.

Webb, Noreen M. (1989), "Peer interaction and learning in small groups," International Journal of Educational Research, 13 (1), 21-39.

Wei, Yinghong Susan and Kwaku Atuahene-Gima (2009), "The moderating role of reward systems in the relationship between market orientation and new product performance in China," International Journal of Research in Marketing, 26 (2), 89-96.

Wieseke, Jan, Christian Homburg, and Nick Lee (2008), "Understanding the adoption of new brands through salespeople: a multilevel framework," Journal of the Academy of Marketing Science, 36 (2), 278-291. 


\section{FOOTNOTES}

${ }^{1}$ We thank an anonymous reviewer for pointing this out. 
FIGURE

Conceptual Model of Customer-Coworker (Im)Balance when Delivering Product-Service Combinations

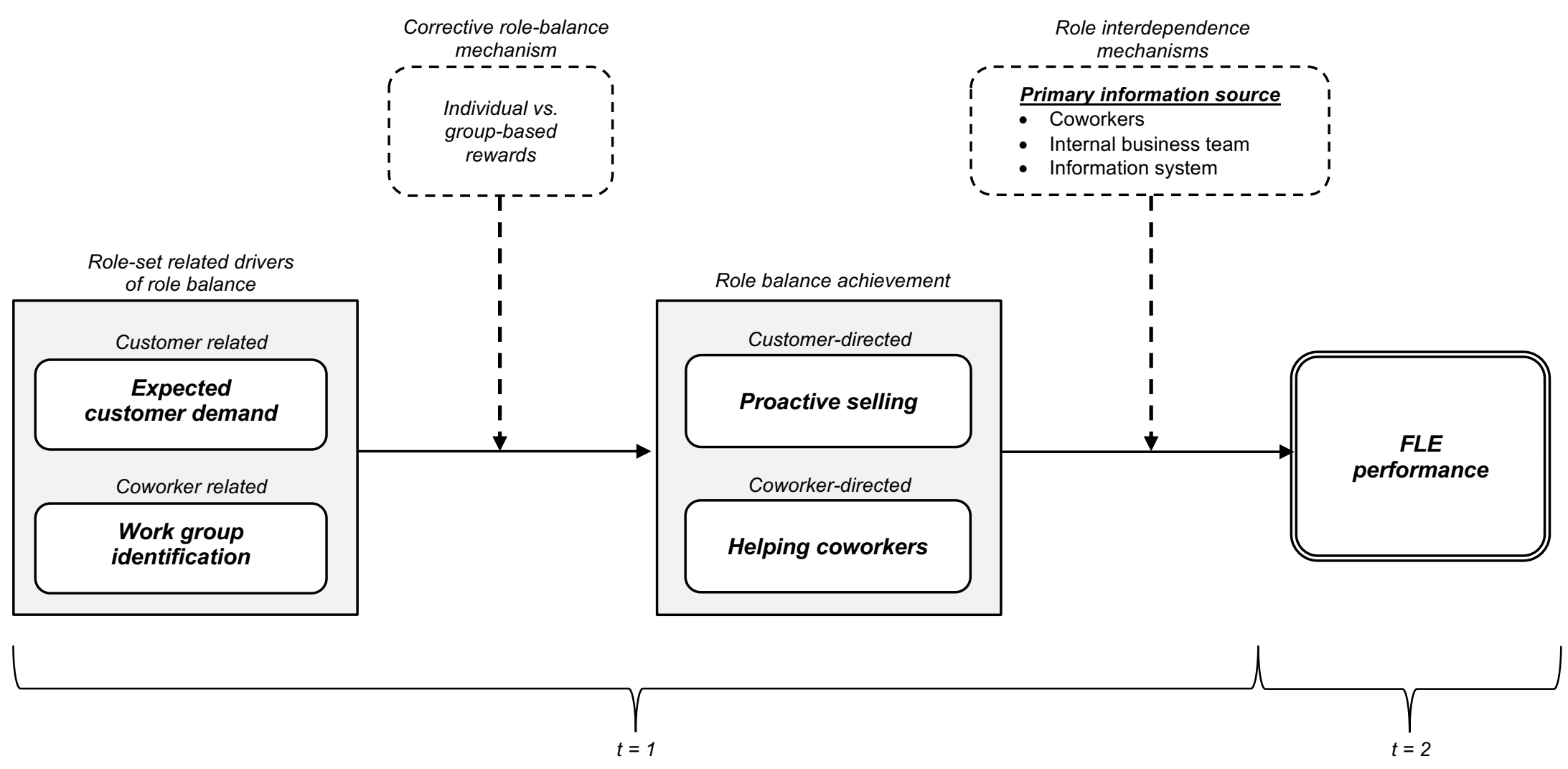


FIGURE 2

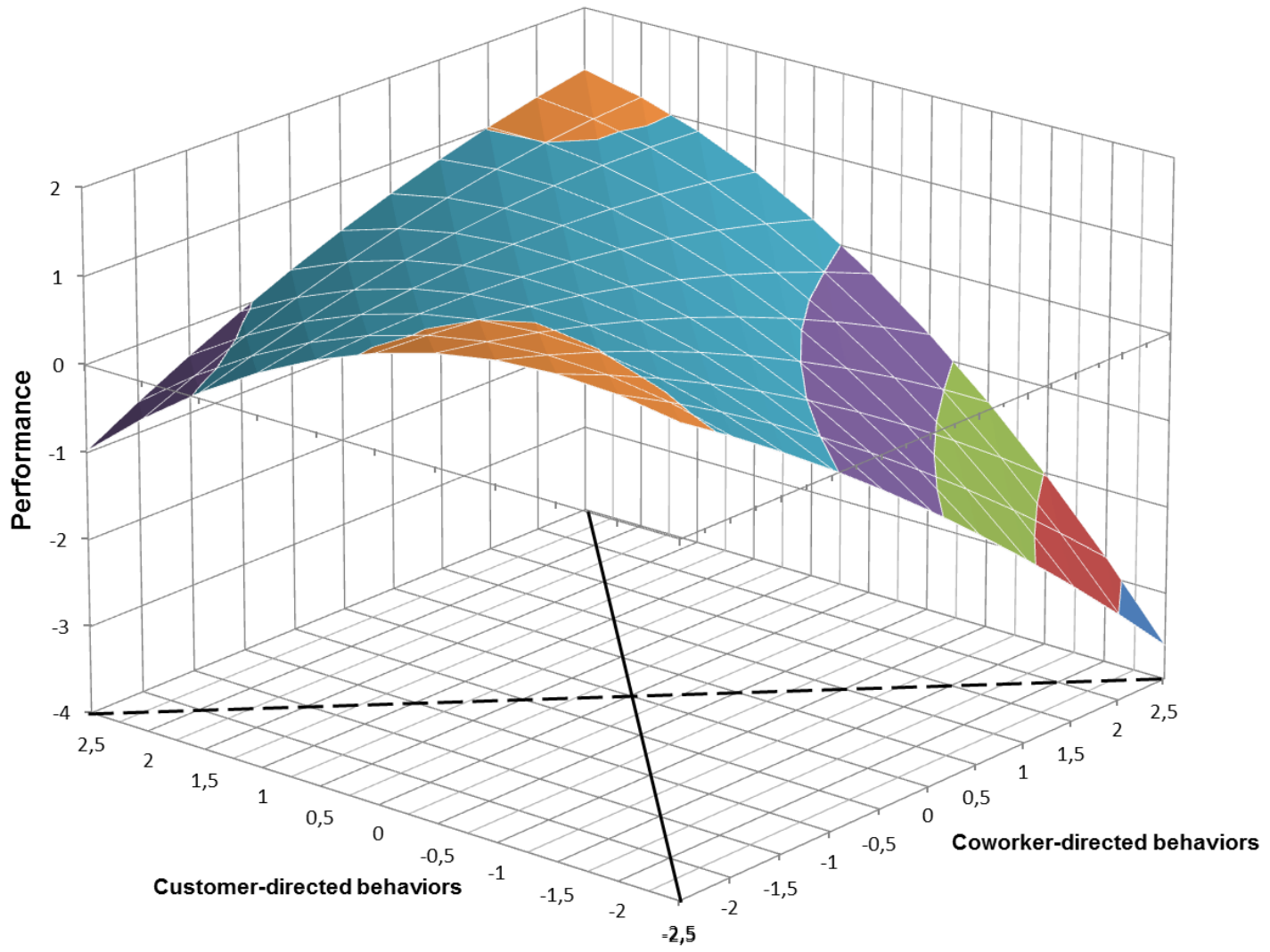

Note: Customer-directed behaviors $=$ proactive selling. Coworker-directed behaviors $=$ helping coworkers. 
FIGURE 3

Impact of (Im)Balance on FLE Performance Under Different Conditions of Primary Information Source Consulted

\section{Panel A: Customer-Coworker Balance}

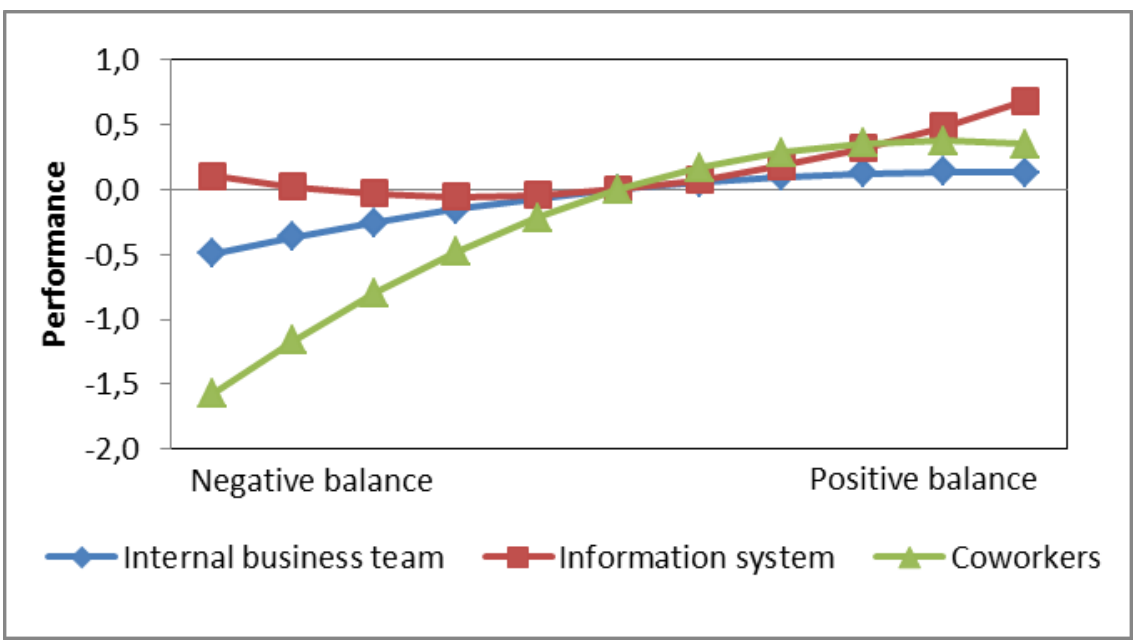

Panel B: Customer-Coworker Imbalance

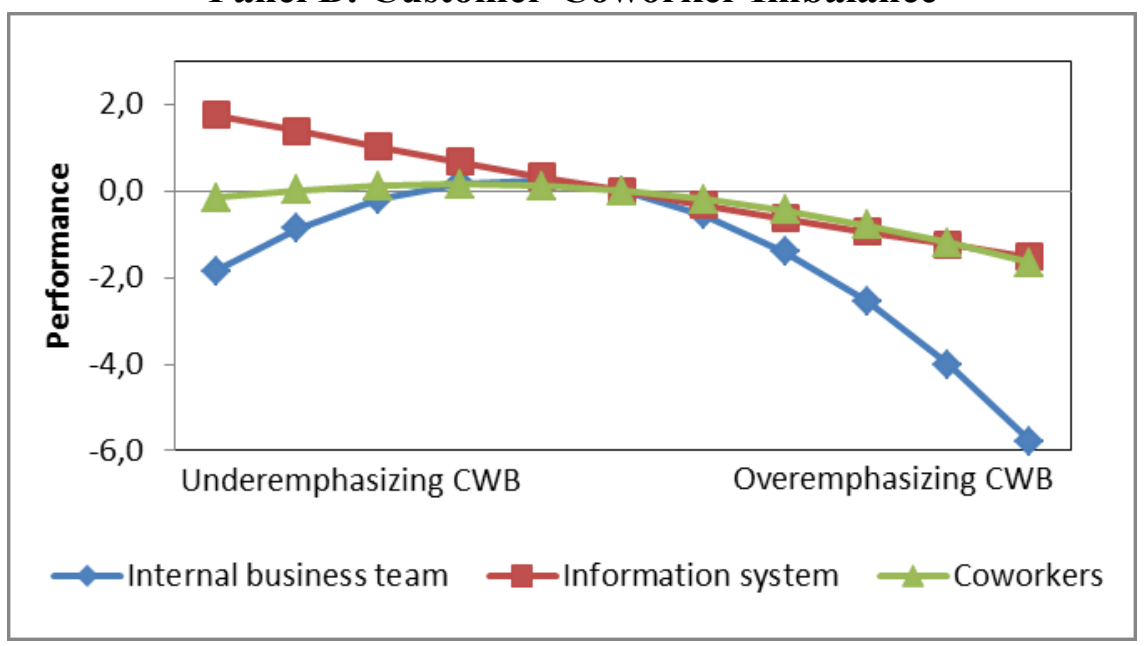

Note: $\mathrm{CWB}=$ coworker-directed behavior (helping coworkers). 
FIGURE 4

The Moderating Role of Group-Based Rewards in Shaping (Im)Balance

\section{Panel A: Effects of Expected Customer Demand}

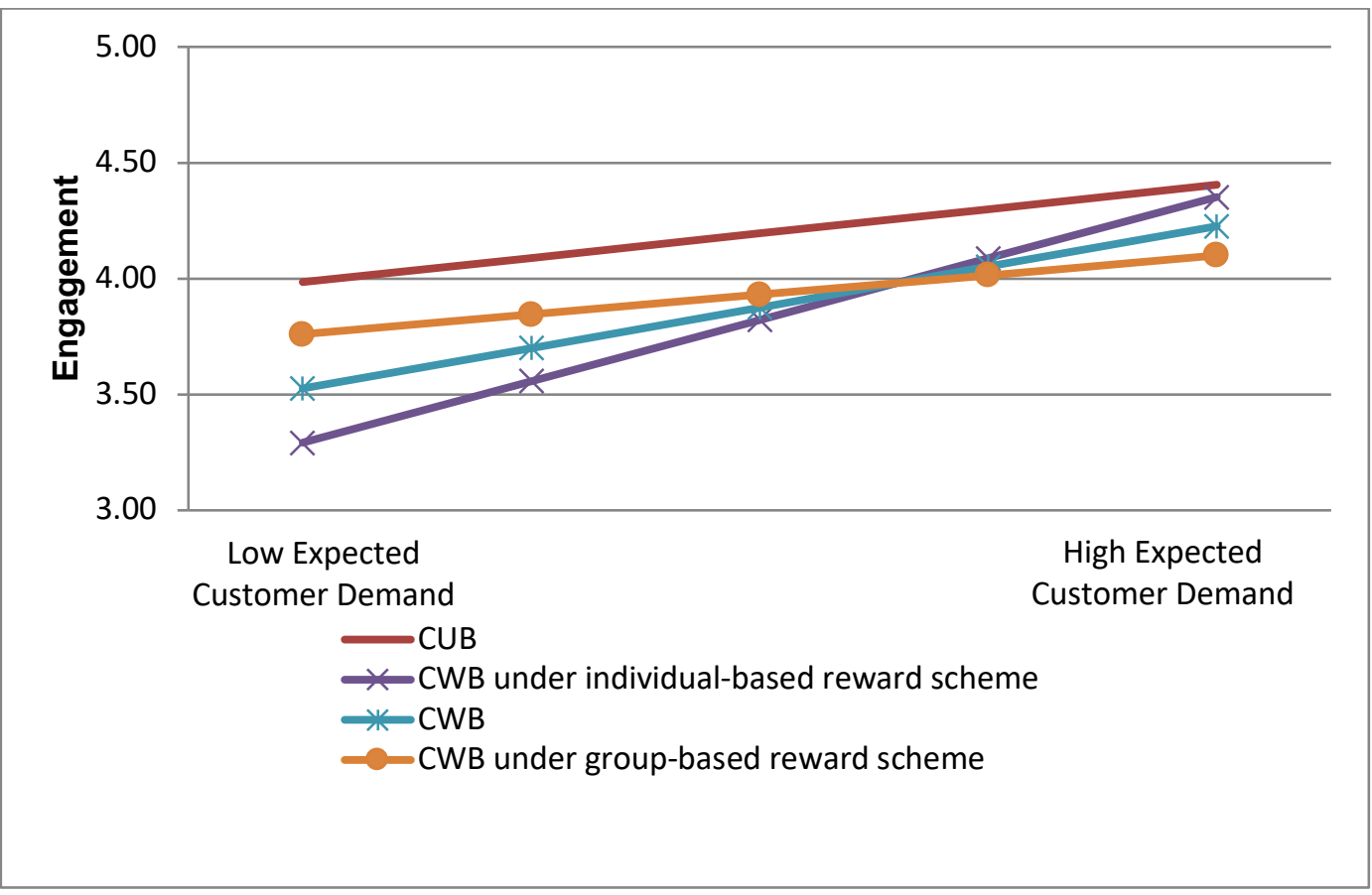

Panel B: Effects of Work Group Identification

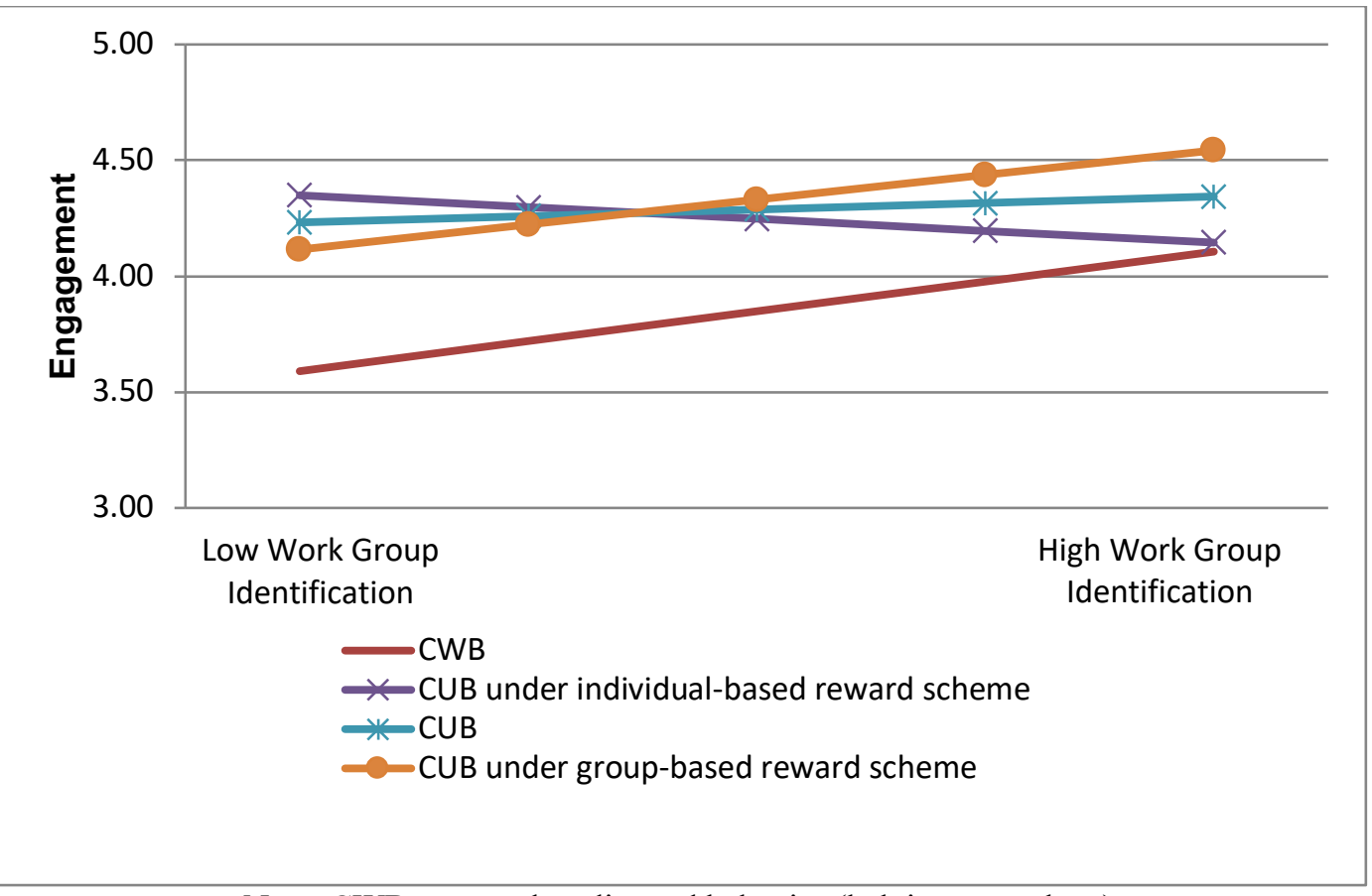

Note: $\mathrm{CWB}=$ coworker-directed behavior (helping coworkers);

CUB $=$ customer-directed behavior (proactive selling). 
TABLE 1

Research in Marketing and Related Disciplines on the Antecedents and Outcomes of Customer and Coworker Directed FLE Behaviors

\begin{tabular}{|c|c|c|c|c|c|c|c|c|}
\hline & \multicolumn{2}{|c|}{ FLE Behaviors } & \multicolumn{2}{|c|}{\begin{tabular}{|c|c|c|}
$\begin{array}{c}\text { Consideration of } \\
\text { Balance }\end{array}$ \\
\end{tabular}} & \multirow{2}{*}{$\begin{array}{c}\text { Outcome } \\
\begin{array}{c}\text { Objective } \\
\text { Performance } \\
\text { measure }\end{array}\end{array}$} & \multirow{2}{*}{$\begin{array}{c}\text { Context } \\
\text { B2B }\end{array}$} & \multirow{2}{*}{$\begin{array}{c}\text { Driver } \\
\text { Hypothesized } \\
\text { Antecedent(s) }\end{array}$} & \multirow{2}{*}{$\begin{array}{l}\text { Contingencies } \\
\text { Hypothesized } \\
\text { Moderator(s) }\end{array}$} \\
\hline & $\begin{array}{c}\text { Coworker } \\
\text { Directed (CWB) }\end{array}$ & $\begin{array}{c}\text { Customer } \\
\text { directed (CUB) }\end{array}$ & $\begin{array}{c}\text { Interaction } \\
\text { CWB and } \\
\text { CUB } \\
\end{array}$ & $\begin{array}{c}\text { Include } \\
\text { nonlinear } \\
\text { effects }\end{array}$ & & & & \\
\hline George (1991) & Altruism & Customer service & & & $\checkmark$ & & Positive mood; Fairness & Moderato(3) \\
\hline MacKenzie, Podsakoff, and Fetter (1991) & Altruism & - & & & $\checkmark$ a & & - & - \\
\hline MacKenzie, Podsakoff, and Fetter (1993) & Altruism & - & & & $\checkmark a$ & & - & - \\
\hline Podsakoff and MacKenzie (1994) & Helping & - & & & & & - & - \\
\hline Settoon, Bennet, and Liden (1996) & $\mathrm{OCB}$ & $\mathrm{b}$ & & & & & $\begin{array}{l}\text { Leader-member exchange; } \\
\text { Perceived organizational } \\
\text { support }\end{array}$ & - \\
\hline Bettencourt and Brown (1997) & Cooperation & Customer service & & & & & $\begin{array}{l}\text { Job satisfaction; Workplace } \\
\text { fairness perceptions }\end{array}$ & - \\
\hline Kelley and Hoffmann (1997) & Altruism & $\begin{array}{l}\text { Customer- } \\
\text { oriented behavior }\end{array}$ & & & & & Employee positive affect & - \\
\hline Netemeyer et al. (1997) & $\begin{array}{l}\text { OCB (incl. } \\
\text { altruism) }\end{array}$ & - & & & & $\checkmark$ & Job satisfaction & - \\
\hline MacKenzie, Podsakoff, and Ahearne (1998) & $\begin{array}{l}\text { OCB (incl. } \\
\text { helping) }\end{array}$ & - & & & $\checkmark$ a & & $\begin{array}{l}\text { Role conflict; Role ambiguity; } \\
\text { Organizational commitment; } \\
\text { Job satisfaction }\end{array}$ & - \\
\hline MacKenzie, Podsakoff, and Paine (1999) & Helping & - & & & $\checkmark$ a & & - & - \\
\hline Piercy et al. (2006) & $\begin{array}{l}\text { OCB (incl. } \\
\text { altruism, team } \\
\text { building) }\end{array}$ & $\begin{array}{l}\text { In-role behavior } \\
\text { performance }\end{array}$ & & & & $\checkmark$ & $\begin{array}{l}\text { Job satisfaction; Sales } \\
\text { manager behavioral control; } \\
\text { Organizational commitment; } \\
\text { Perceived organizational } \\
\text { support }\end{array}$ & - \\
\hline Mulki, Jaramillo, Marshall (2007) & Helping & Task performance & & & & $\checkmark$ & Lone wolf tendencies & - \\
\hline Netemeyer and Maxham III (2007) & $\begin{array}{l}\text { Employee-directed } \\
\text { extra role }\end{array}$ & $\begin{array}{c}\text { Customer- } \\
\text { directed behavior }\end{array}$ & & $\checkmark$ & & $\checkmark$ & Customer justice measures & - \\
\hline Restubog, Bordia, and Tang (2007) & OCB & - & & & & & Breach & Equity sensitivity (D) \\
\hline Cohen and Keren (2003) & Altruism & b & & & & & $\begin{array}{l}\text { Justice; Commitment; } \\
\text { Individual values }\end{array}$ & - \\
\hline Vilela, Gonzalez, and Ferrin (2008) & OCB & - & & & & $\checkmark$ & $\begin{array}{l}\text { Satisfaction; Organizational } \\
\text { commitment }\end{array}$ & - \\
\hline Kim, Tavitiyaman, and Kim (2009) & Cooperation & Customer service & & & & & Job satisfaction & - \\
\hline Raub and Robert (2010) & Helping & Service behavior & & & & & $\begin{array}{l}\text { Empowering leader behaviors; } \\
\text { Psychological empowerment }\end{array}$ & Power values (D) \\
\hline Agnihotri, Krush, and Singh (2012) & Helping & $\begin{array}{l}\text { Customer } \\
\text { relationship } \\
\text { performance }\end{array}$ & & & & $\checkmark$ & $\begin{array}{l}\text { Empathy proneness; Guilt } \\
\text { proneness }\end{array}$ & - \\
\hline
\end{tabular}


TABLE 1 Continued

Research in Marketing and Related Disciplines on the Antecedents and Outcomes of Customer and Coworker Directed FLE Behaviors

\begin{tabular}{|c|c|c|c|c|c|c|c|c|}
\hline Cohen, Ben-Tura, and Vashdi (2012) & Altruism & b & & & & & Commitment; Leadership & $\begin{array}{l}\text { Social cohesion (D); Group size } \\
\text { (D) }\end{array}$ \\
\hline Marshall et al. (2012) & $\mathrm{OCB}$ & $\begin{array}{c}\text { Customer } \\
\text { orientation }\end{array}$ & & & $\checkmark$ & $\checkmark$ & Organizational commitment & - \\
\hline Rapp, Bachrach, and Rapp (2013) & Helping & Customer service $^{\mathrm{c}}$ & & $\checkmark$ & $\checkmark$ & $\checkmark$ & - & Time management skills $(\mathrm{O})$ \\
\hline Malhotra and Ackfeldt (2016) & Cooperation & Customer service & & & & & $\begin{array}{l}\text { Role ambiguity; } \\
\text { Organizational commitment; } \\
\text { Role conflict }\end{array}$ & - \\
\hline Rodwell, McWilliams, and Gulyas (2017) & OCB & b & & & & & Work engagement & - \\
\hline Cheng and Chen (2017) & $\begin{array}{l}\text { Employee } \\
\text { cooperation }\end{array}$ & Customer service & & & & & $\begin{array}{l}\text { Job resourcefulness; Work } \\
\text { engagement }\end{array}$ & - \\
\hline Liao, Wayne, Liden, and Mueser (2017) & Helping & b & & & & & Leader-member exchange & - \\
\hline Van der Borgh, De Jong, and Nijssen (2017b) & Helping & - & & & & $\checkmark$ & Work group identification & Sales experience \\
\hline Current study & Helping & Proactive selling & $\checkmark$ & $\checkmark$ & $\checkmark$ & $\checkmark$ & $\begin{array}{l}\text { Expected customer demand; } \\
\text { Work group identification }\end{array}$ & $\begin{array}{l}\text { Work group-based rewards }(D) \text {; } \\
\text { Primary information source }(O)\end{array}$ \\
\hline
\end{tabular}

a This study did not consider objective sales performance as an outcome of FLE behavior, but instead focused on explaining other outcomes (e.g., overall managerial

evaluation of FLE performance, FLE turnover).

b This study did measure task-related FLE behaviors (e.g., in-role behaviors), but did not focus specifically on customer-directed behaviors.

${ }^{c}$ This study considered this measure as an outcome of coworker directed behavior.

Notes: $\mathrm{OCB}=$ Organizational citizenship behaviors; $\mathrm{O}=$ moderation behavior-performance relationship; $\mathrm{D}=$ moderating antecedent-behavior relationship.

This overview focuses on studies that consider coworker directed measures. We do not consider the plethora of articles focusing merely on customer directed FLE behaviors as our interest lies in understanding how coworker directed behaviors affect individual FLE performance above and beyond customer directed behaviors. We direct interested readers to some of the meta-studies focusing on customer directed behaviors (e.g., Verbeke, Dietz, and Verwaal 2011). 
TABLE 2

Intercorrelation Matrix of Focal Constructs

\begin{tabular}{|c|c|c|c|c|c|c|c|c|c|c|c|c|c|c|c|c|}
\hline \multicolumn{2}{|c|}{ Variables } & 1 & 2 & 3 & 4 & 5 & 6 & 7 & 8 & 9 & 10 & 11 & 12 & 13 & 14 & 15 \\
\hline 1 & Expected customer demand (ECD) & & & & & & & & & & & & & & & \\
\hline 2 & Work group identification (WID) & $.22^{* *}$ & & & & & & & & & & & & & & \\
\hline 3 & Perceived work group efficacy & .09 & $.50^{\star *}$ & & & & & & & & & & & & & \\
\hline 4 & Work group-based rewards (GBR) & .12 & $.25^{* *}$ & $.19^{*}$ & & & & & & & & & & & & \\
\hline 5 & Info from internal business team & .14 & -.09 & -.01 & .00 & & & & & & & & & & & \\
\hline 6 & Info from information system & -.10 & -.08 & -.01 & -.06 & -.08 & & & & & & & & & & \\
\hline 7 & Info from work group members & .02 & .08 & .07 & $.17^{*}$ & $-.19^{*}$ & $-.17^{*}$ & & & & & & & & & \\
\hline 8 & Job experience & .07 & .12 & .05 & .06 & .12 & .10 & .00 & & & & & & & & \\
\hline 9 & Work group tenure & $.17^{*}$ & $.17^{*}$ & .12 & -.01 & .00 & .08 & -.04 & $.23^{\star \star}$ & & & & & & & \\
\hline 10 & Task autonomy & .07 & .06 & $.19^{*}$ & .12 & .02 & .04 & -.04 & -.06 & -.02 & & & & & & \\
\hline 11 & Organizational identification & $.28^{* *}$ & $.29^{* *}$ & .12 & .01 & -.01 & $-.20^{* \star}$ & $*-01$ & .12 & $.22^{* *}$ & -.03 & & & & & \\
\hline 12 & $\%$ new clients & .11 & -.04 & -.01 & $.16^{*}$ & .03 & $-.15^{\star}$ & -.05 & -.11 & -.10 & .04 & -.06 & & & & \\
\hline 13 & Coworker-directed behaviors (CWB) & $.23^{* *}$ & $.39^{* *}$ & $.40^{\star *}$ & $.22^{\star *}$ & -.10 & -.09 & -.02 & .08 & $.24^{\star *}$ & $.17^{*}$ & $.30^{\star \star}$ & $.19^{*}$ & & & \\
\hline 14 & Customer-directed behaviors (CUB) & $.25^{* *}$ & $.21^{* *}$ & $.30^{* *}$ & .08 & .00 & $-.18^{\star \star}$ & $*-.07$ & .00 & .11 & $.22^{* *}$ & $.28^{* \star}$ & $.22^{* *}$ & $.62^{\star *}$ & & \\
\hline & FLE Performance & $.25^{\star *}$ & .04 & .01 & .04 & $.17^{*}$ & -.09 & -.14 & .03 & .10 & .09 & -.04 & $.34^{\star *}$ & $.18^{*}$ & $.20^{*}$ & \\
\hline $\mathrm{Me}$ & & 3.15 & 4.02 & 4.17 & 3.41 & .24 & .30 & .59 & 12.38 & 3.50 & 3.83 & 3.68 & 27.88 & 3.79 & 4.19 & 25.29 \\
\hline SD & & .74 & .82 & .71 & 1.04 & .43 & .46 & .49 & 6.77 & 2.83 & .85 & .76 & 3.01 & .78 & .75 & 28.26 \\
\hline
\end{tabular}


TABLE 3

Descriptive Meta-analytic Triangulation of Relations between Coworker-directed behaviors, Customer-directed behaviors, and Individual Job Performance Research

\begin{tabular}{|c|c|c|c|c|c|}
\hline Study & $\begin{array}{l}\text { Customer directed } \\
\text { - coworker } \\
\text { directed }\end{array}$ & $\begin{array}{l}\text { Coworker } \\
\text { directed - Job } \\
\text { performance }\end{array}$ & $\begin{array}{l}\text { Customer } \\
\text { directed - Job } \\
\text { performance }\end{array}$ & & \\
\hline Meta-analysis & Fisher's Zr & Fisher's Zr & Fisher's Zr & & \\
\hline Podsakoff et al. (2009) & $\begin{array}{l}.41^{\mathrm{b}} \\
(\mathrm{n}=12,649 \\
\mathrm{k}=37)\end{array}$ & $\begin{array}{l}.22^{b} \\
(n=4,052 \\
k=10)\end{array}$ & $\begin{array}{l}.34^{\mathrm{b}} \\
(\mathrm{n}=4,224 \\
\mathrm{k}=11)\end{array}$ & & \\
\hline FLE studies & Fisher's Zr & Fisher's Zr & Fisher's Zr & $n$ & Industry \\
\hline George (1991) & $.59^{b}$ & $-.11^{\mathrm{c}}$ & $.20^{\mathrm{c}}$ & 221 & Retail \\
\hline Bettencourt and Brown (1997) ${ }^{d}$ & $.99^{\mathrm{b}}$ & - & - & 232 & Banking \\
\hline Bettencourt and Brown (1997) & $.89^{b}$ & - & - & 232 & Banking \\
\hline Kelley and Hoffmann (1997) & $.43^{\mathrm{b}}$ & - & $.27^{\mathrm{b}}$ & 122 & Banking \\
\hline Piercy et al. (2006) & $.46^{\mathrm{b}}$ & $.14^{\mathrm{b}}$ & $.48^{\mathrm{b}}$ & 214 & Publishing \\
\hline Mulki, Jaramillo, Marshall (2007) & $.29^{\mathrm{b}}$ & - & - & 331 & Pharma \\
\hline Netemeyer and Maxham III (2007) & $.73^{\mathrm{b}}$ & $.33^{\mathrm{c}}$ & $.68^{\mathrm{c}}$ & 132 & Retail \\
\hline Netemeyer and Maxham III (2007) & $.23^{\mathrm{b}}$ & $.07^{\mathrm{c}}$ & $.12^{\mathrm{c}}$ & 132 & Retail \\
\hline Netemeyer and Maxham III (2007) & $.58^{\mathrm{b}}$ & $.38^{\mathrm{c}}$ & $.69^{c}$ & 320 & Retail \\
\hline Netemeyer and Maxham III (2007) & $.16^{\mathrm{b}}$ & $.05^{\mathrm{c}}$ & $.27^{\mathrm{c}}$ & 320 & Retail \\
\hline Kim, Tavitiyaman, Kim (2009) & $.58^{\mathrm{b}}$ & - & - & 194 & Hotel \\
\hline Raub and Robert (2010) & $.91^{\mathrm{b}}$ & - & - & 541 & Hotel \\
\hline Agnihotri et al. (2012) & $.02^{\mathrm{b}}$ & $.52^{\mathrm{b}}$ & $.30^{\mathrm{b}}$ & 125 & Media \\
\hline Marshall et al. (2012) & $.33^{\mathrm{b}}$ & $.12^{\mathrm{b}}$ & $.03^{\mathrm{b}}$ & 207 & Cleaning \& shipping \\
\hline Rapp et al. (2013) & $.25^{\mathrm{b}}$ & $.25^{\mathrm{c}}$ & $.20^{\mathrm{c}}$ & 212 & Hospitality \\
\hline Malhotra and Ackfeldt (2016) & $.68^{\mathrm{b}}$ & - & - & 184 & Travel \\
\hline Cheng and Chen (2017) & $.66^{\mathrm{b}}$ & - & - & 282 & Hotel \\
\hline Aggregated effect size: & .51 & .19 & .28 & 4,001 & \\
\hline The present study & $.72^{\mathrm{b}}$ & $.18^{\mathrm{c}}$ & $.20^{\mathrm{c}}$ & 180 & ICT industry \\
\hline $\begin{array}{l}\text { Task performance in the Podsakoff et al } \\
\text { FLEs and other employees; }{ }^{b}=\text { same data } \\
\text { service; } \mathrm{f}=\text { Supervisor rated; } \mathrm{g}=\text { Employe } \\
\text { Notes: } \mathrm{n}=\text { sample size; } \mathrm{k}=\text { number of sar }\end{array}$ & $\begin{array}{l}\text { 009) study also includ } \\
\text { urce; }{ }^{c}=\text { different data } \\
\text { ated. } \\
\text { les. }\end{array}$ & $\begin{array}{l}\text { non-customer di } \\
\text { ource; }{ }^{d}=\text { Extra-r }\end{array}$ & $\begin{array}{l}\text { ted tasks as the } \mathrm{s} \\
\text { customer service }\end{array}$ & $\begin{array}{l}\text { dy does } \\
e=\text { Role }\end{array}$ & $\begin{array}{l}\text { not differentiate betwe } \\
\text { prescribed customer }\end{array}$ \\
\hline
\end{tabular}


TABLE 4

Polynomial Regression Results for FLE Performance

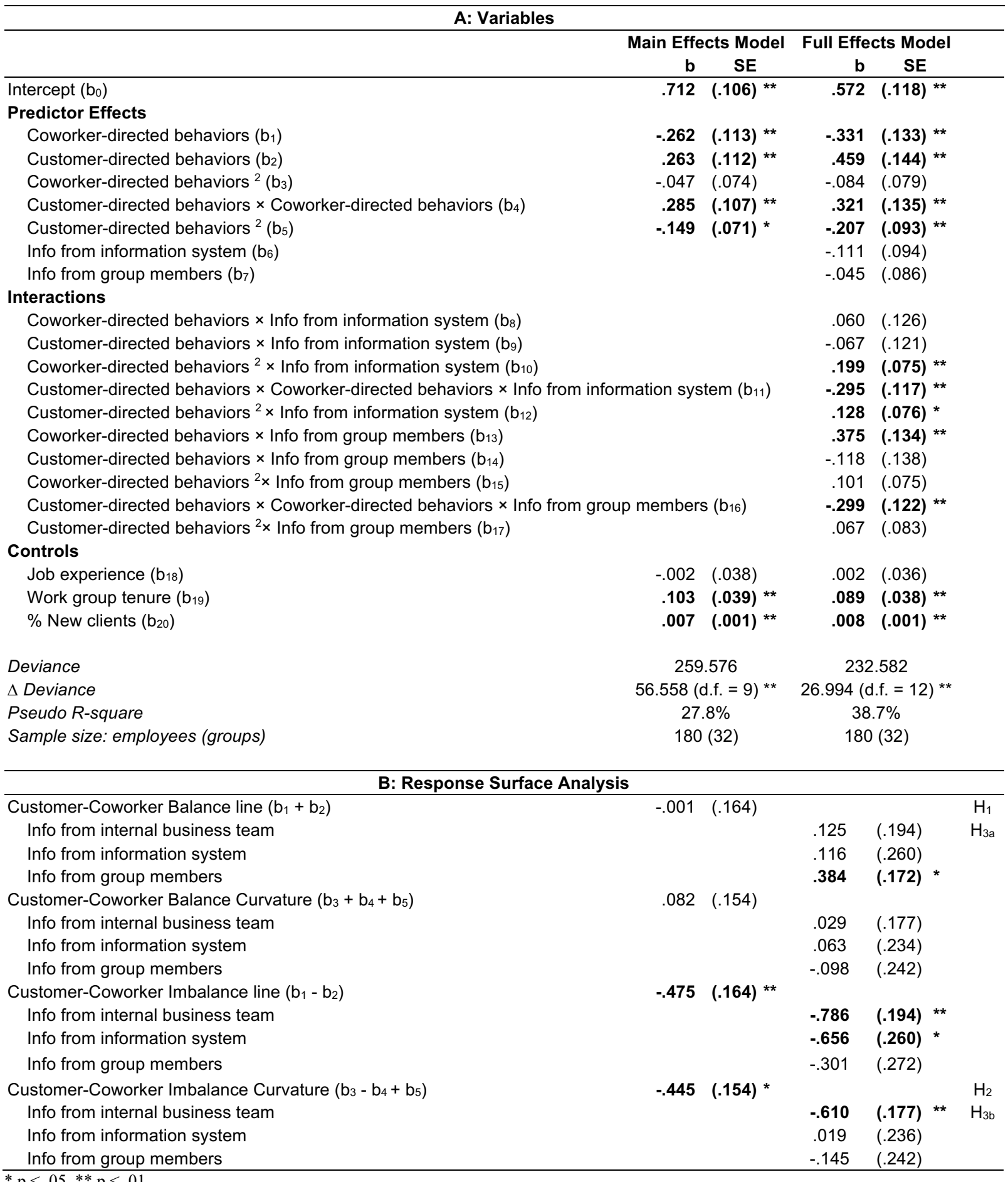

$* \mathrm{p}<.05 . * * \mathrm{p}<.01$

Notes: Customer-directed behaviors $=$ proactive selling. Coworker-directed behaviors $=$ helping coworkers. This table reports unstandardized coefficients, with standard errors in parentheses. Significant coefficients based on one-tailed tests are in bold. SE = standard error. 
TABLE 5

Multivariate Hierarchical Regression Results for Drivers of (Im)Balance

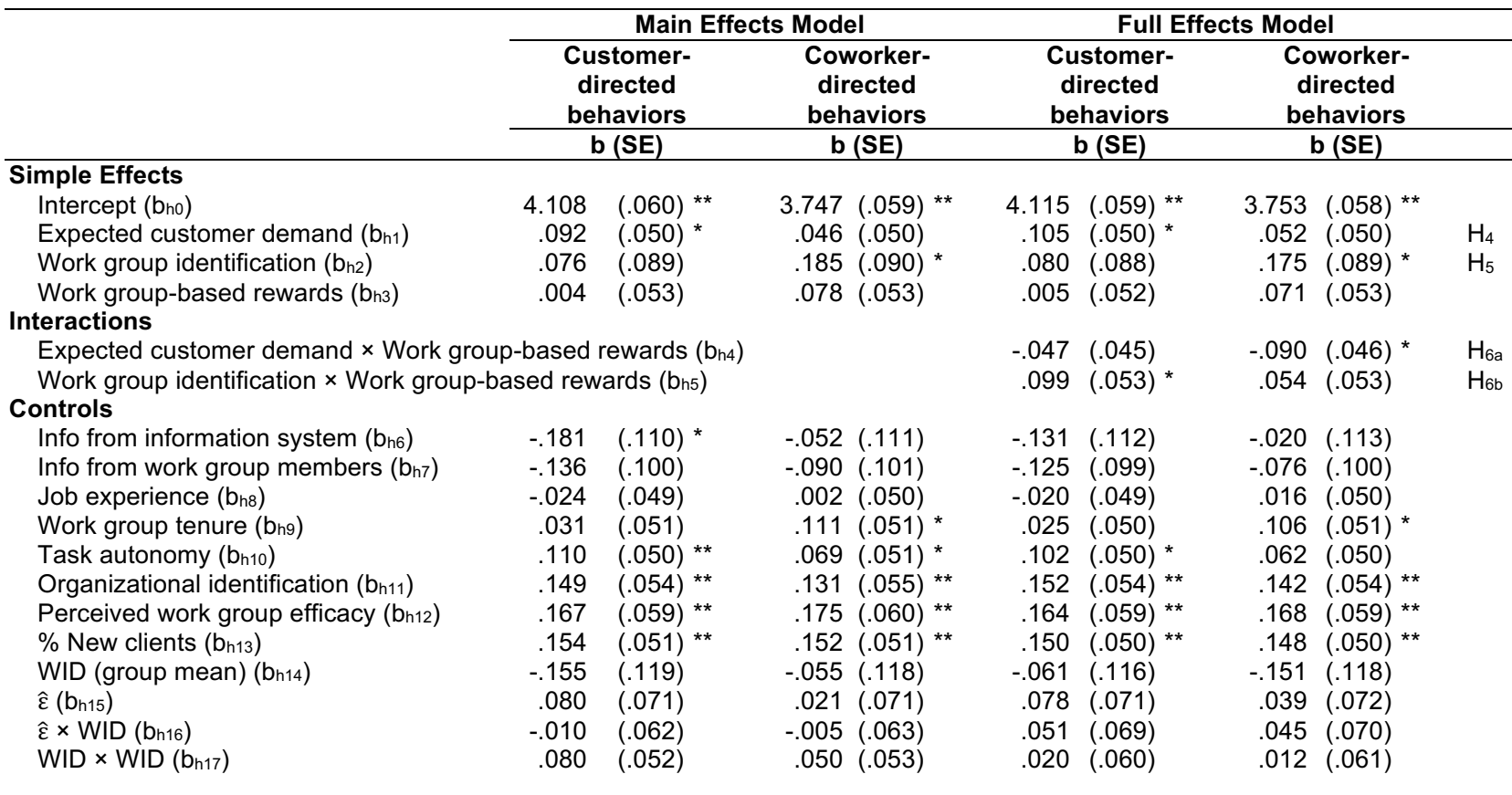

Notes: Customer-directed behaviors $=$ proactive selling. Coworker-directed behaviors $=$ helping coworkers. This table reports unstandardized coefficients, with standard errors in parentheses. Significant coefficients based on one-tailed tests are in bold. $\mathrm{h}=1$ for customer-directed behaviors, 2 for coworker-directed behaviors. $\mathrm{n}($ level 1) $=180$ FLEs; $\mathrm{N}($ level 2$)=32$ work groups. SE $=$ standard error. $\widehat{\varepsilon}, \hat{\varepsilon} \times$ WID, and WID $\times$ WID allow us to control for biases in estimates due to endogeneity. The nonsignificant results of these three coefficients indicate that there is no concern for endogeneity bias, which is consistent with the Durbin and Wu-Hausman test results. Estimates without these parameters provide similar results thereby corroborating the robustness of our model and findings, but for the sake of completeness we report the full model including endogeneity control. 


\section{Appendix \\ Measurement Scales}

Expected customer demand $(n=4 ; C R=.91 ;$ AVE $=.64)$

Factor Loading

The following questions focus on new product-service solutions introduced by your company.

Please indicate your expectancies for products during their introduction concerning...

the size of the order intake.

the sales volume.

.86

the size of the revenue.

the size of the profits.

Work group identification $(n=4 ; C R=.77 ; A V E=.52)$

I strongly identify with the other members of my group. $\quad .69$

I would like to continue working with my group.

I feel emotionally attached to this group. $\quad .82$

I dislike being a member of this group. $[R]^{\mathrm{a}}$

Work group-based reward $(n=3 ; C R=.86 ; A V E=.67)$

The pay scheme strongly motivates me to achieve group performance goals.

I am keenly aware how to maximize the group-based part in my payment.

I am strongly motivated by the group-based pay scheme to be innovative and entrepreneurial.

Customer-directed behaviors (Proactive selling scale) $(n=5 ; C R=.93 ; A V E=.74)$

The following questions focus on new product-service solutions introduced by your company.

Within group Y, I am the one who...

does not give up easily when encountering a customer to whom it is difficult to sell products.

always anticipates potential problems with selling products.

is constantly on the lookout to identify opportunities to sell products.

actively scans the need for products.

Coworker-directed behaviors (Helping scale) $(n=5$; $C R=.89$; AVE $=.61$ )

The following questions focus on new product-service solutions introduced by your company.

Within group $\mathrm{Y}, \mathrm{I}$ am the one who...

helps a group member if $\mathrm{s} / \mathrm{he}$ falls behind in selling the products.

shares his/her expertise about the products with group members.

"touches base" with other group members before initiating actions that might affect them in selling the products.

encourages other group members when they are behind in selling of the products.

willingly gives of my time to help group members who have problems with selling the products.

Organizational identification $(n=6 ; C R=.87 ; A V E=.53)$

When someone criticizes 'company $X$ ', it feels like a personal insult. $\quad .70$

I am very interested in what others think about 'company X'.

When I talk about 'company X', I usually say "we" rather than "they." $\quad .75$

'Company X's' successes are my successes.

When someone praises 'company X', it feels like a personal compliment. $\quad .89$

If a story in the media criticized 'company X', I would feel embarrassed.

Perceived work group efficacy $(n=4 ; C R=.87 ; A V E=.64)$

Our group has the necessary skills to sell products to customers.

In comparison to other groups, the selling approach of our team for products is first-rate.

Our group can set and achieve challenging sales objectives for products.

Our group is able to deal effectively with any selling problem that may occur with products.

Task Autonomy $(n=4 ; C R=.83 ; A V E=.56)$

I am allowed complete freedom in selling products.

I am allowed to sell products the way I think best.

I am permitted to use my own judgment in selling products. $\quad .76$

$\begin{array}{ll}\text { I am allowed a high degree of initiative in selling products. } & .78\end{array}$ 